\title{
Elastic buckling of elliptical tubes
}

\author{
A. M. Ruiz-Teran ${ }^{1}$ L. Gardner ${ }^{2}$
}

${ }^{1}$ Assistant Professor, Department of Civil Engineering and Building. University of Castilla-La Mancha. Av. Camilo Jose Cela s/n. 13071 Ciudad Real, Spain. Visiting academic at Imperial College London. Email: aruiter@ ciccp.es

${ }^{2}$ Corresponding author, Senior Lecturer in Structural Engineering, Department of Civil and Environmental Engineering. Imperial College London. SW7 2AZ London, United Kingdom. Email: Leroy.gardner@imperial.ac.uk

\begin{abstract}
Hot-rolled and cold-formed structural steel tubular members of elliptical cross-section have recently been introduced into the construction sector. However, there is currently limited knowledge of their structural behaviour and stability, and comprehensive design guidance is not yet available. This paper examines the elastic buckling response of elliptical hollow sections in compression, which has been shown to be intermediate between that of circular hollow sections and flat plates. The transition between these two boundaries is dependant upon both the aspect ratio and relative thickness of the section. Based on the results of numerical and analytical studies, formulae to accurately predict the elastic buckling stress of elliptical tubes have been proposed, and shortcomings of existing expressions have been highlighted. Length effects have also been investigated. The findings have been employed to derive slenderness parameters in a system of cross-section classification for elliptical hollow sections, and form the basis for the development of effective section properties for slender elliptical tubes.
\end{abstract}




\section{Keywords}

Buckling; cross-section; elliptical hollow sections; instability; local buckling; oval hollow sections; structures; tubular structures.

\section{Introduction}

The use of structural tubes of elliptical form dates back to the mid-nineteenth century. In the initial designs of the Britannia Bridge developed in 1845, elliptical sections were considered for the compression flange of the main box girder [1, 2], whilst the primary arched compression elements of the Royal Albert Bridge, designed by Brunel and constructed in 1859, were of elliptical form and fabricated from wrought iron plates [3]. Elliptical hollow sections (EHS) are now available as hot-rolled and cold-formed structural members and have recently begun to appear in steel construction. Recent examples include several canopies and buildings, such as the coach station at Terminal 3 and the main building at Terminal 5 of Heathrow Airport in London [4] and the main building at Terminal 4 of Barajas Airport in Madrid (Figure 1) [5], as well as bridges, such as the Highland Society Bridge in Braemar, Scotland [6]. From an architectural perspective, these new sections offer an interesting and unusual appearance, whilst from the structural standpoint, they possess differing flexural rigidities about each of the principal axes (allowing the sections to be orientated to most efficiently resist the applied loading) as well as high torsional stiffness.

In this paper the elastic buckling of elliptical tubes is examined, and following a review of previous investigations carried out on EHS, analytical and numerical studies are presented. A simple analytical model has been developed to describe the boundary 
Cite this paper as: Ruiz-Teran AM, Gardner L, 2008, Elastic buckling of elliptical tubes, Thin-Walled

Structures, Vol:46, ISSN:0263-8231, Pages:1304-1318 [DOI: 10.1016/j.tws.2008.01.036]

behaviour (CHS and flat plates) and intermediate behaviour of elliptical sections. The model provides insight into the transitional behaviour of an EHS between the two boundaries and explains the role and significance of the key geometrical parameters aspect ratio, relative thickness and length. A supporting numerical study, using the finite element package ABAQUS, has also been performed. Based on the findings of the numerical and analytical investigations, and towards the establishment of efficient structural design rules, formulae to accurately predict the elastic buckling stress of compressed EHS of varying proportions are presented. The resulting formulae have been utilised to define slenderness measures within an established system of crosssection classification for EHS, which was developed in [7], and form the basis for the development of effective section properties for slender elliptical tubes.

\section{Background}

The earliest investigations into the buckling response of compressed non-circular hollow sections (NCHS) were conducted in the second half of the twentieth century using analytical methods. The first study, performed by Marguerre in 1951 [8], focussed on cylindrical shells of varying curvature defined by Fourier polynomial terms, the simplest geometry of which were described through Eq. (1).

$$
\frac{1}{\mathrm{r}}=\frac{1}{\mathrm{r}_{0}}\left(1+\xi \cos \left(\frac{4 \pi \mathrm{s}}{\mathrm{L}_{0}}\right)\right)
$$

where $\mathrm{r}$ is the radius of curvature at the point $\mathrm{s}$ along the curved length of the section, $\xi$ is the eccentricity of the section, $\mathrm{L}_{0}$ is the perimeter of the section and $\mathrm{r}_{0}$ is the radius of a circular section with the same perimeter. Marguerre showed that a NCHS defined by Eq. (1) was of comparable shape to an ellipse provided $0 \leq \xi \leq 1$. For $\xi=0$, Eq. (1) exactly represents a circular hollow section (CHS), whilst for $\xi=1$, the maximum radius of curvature of the NCHS is equal to infinity and the aspect ratio of the section 
Cite this paper as: Ruiz-Teran AM, Gardner L, 2008, Elastic buckling of elliptical tubes, Thin-Walled Structures, Vol:46, ISSN:0263-8231, Pages:1304-1318 [DOI: 10.1016/j.tws.2008.01.036]

(ratio between the major and minor axes lengths) is equal to 2.06. With the restriction that $0 \leq \xi \leq 1$, the NCHS described by Eq. (1) have generally been referred to in previous research as oval hollow sections (OHS). Marguerre [8] obtained the elastic buckling stresses and the buckled mode shapes of OHS defined by Eq. (1), by means of an assumed deflection function. The maximum deflection was found to be close to, but not at, the point of maximum radius of curvature. Exactly at the point of maximum radius of curvature, the deflection was zero. In 1962, Kempner [9] examined the buckling response of OHS using a different deflection function to Marguerre and concluded that the elastic buckling stress could be accurately predicted as the buckling stress of a circular hollow section (CHS) with a radius equal to the maximum radius of curvature of the OHS and that the solution was a lower bound. The maximum deflection was found to occur at the point of maximum radius of curvature, contrary to Marguerre's results. The effect of length on the buckling behaviour of OHS tubes with clamped ends was studied by Feinstein et al. [10] who observed noticeable deviations in elastic buckling stress from the case of tubes of infinite length.

In 1964, Kempner and Chen [11] analysed the post-buckling behaviour of OHS, finding that the higher the aspect ratio of the OHS, the more stable the post-buckling behaviour (approaching a plate-like response) and, the lower the aspect ratio, the more unstable the post-buckling behaviour (approaching a CHS shell-like response). It was also found that the smaller the ratio between the radius $r_{0}$ and the thickness $t$, the less stable the postbuckling behaviour. Kempner and Chen [12] later showed that load carrying capacities above the bifurcation load would be attained for OHS with high aspect ratios, due to the redistribution of stresses to the stiff major axis regions of high curvature of the section. 
Cite this paper as: Ruiz-Teran AM, Gardner L, 2008, Elastic buckling of elliptical tubes, Thin-Walled Structures, Vol:46, ISSN:0263-8231, Pages:1304-1318 [DOI: 10.1016/j.tws.2008.01.036]

The buckling and initial post-buckling behaviour of elliptical hollow sections was first studied by Hutchinson [13] in 1968. Hutchinson concluded that Kempner's proposal whereby the elastic buckling stress of an OHS could be accurately predicted using the classical CHS formulation with an equivalent radius equal to the maximum radius of curvature of the OHS, may also be applied to EHS, provided the shell is sufficiently thin. Hutchinson also found EHS to generally have unstable post-buckling behaviour with the consequence of high imperfection sensitivity, which was contradictory to the findings of Kempner and Chen [12] for OHS. However, upon extending his study to OHS, Hutchinson [13] found this disparity to be related not to the differences in geometry between the considered oval and ellipse, but to the choice of deflection function used in the two analytical studies, and asserted that Kempner and Chen's deflection function was not suitable for examining the initial post-buckling region. In the same year, Kempner and Chen [14] extended their previous work [12] and concluded that for OHS with small eccentricities, imperfection sensitivity was indeed high, whilst for larger eccentricities post-buckling behaviour was stable, loads in excess of the elastic buckling load could be attained and sensitivity to imperfections was lower.

In 1971, Tennyson et al. [15] carried out physical tests to assess the buckling behaviour of EHS with aspect ratios between 1 and 2. The tests confirmed both Hutchinson's conclusions [13] regarding the high imperfection sensitivity of elliptical shells of aspect ratio close to unity and Kempner and Chen's conclusions [14] concerning the attainment of loads beyond the elastic buckling load for EHS with larger aspect ratios. In 1976, Tvergaard [16] showed that the extra load carrying capacity above the bifurcation load that had been predicted by Kempner and Chen [12, 14] and substantiated by the tests of Tennyson [15] may not achieved when elastic-plastic material behaviour is considered, due to premature yielding of the major axis regions. 
Tvergaard [16] also found that high aspect ratio elastic-plastic OHS were moderately imperfection sensitive, whilst the lower the aspect ratio, the greater the imperfection sensitivity.

With the emergence of steel EHS of structural proportions, a number of recent studies have been performed. Following preliminary experimental and numerical investigations $[17,18]$, extensive studies of EHS under axial compression and bending were carried out by Chan and Gardner [19, 20] and a system of cross-section slenderness limits was established [7]. For compressive loading, these studies have confirmed that Kempner's approach of basing the elastic buckling load of an EHS on that of a CHS with a radius equal to the maximum radius of curvature of the ellipse is acceptable $[19,21]$. However, it is shown later in this paper that this approach becomes overly conservative for many geometries, and simple formulae to more accurately predict the buckling stress of EHS are presented.

\section{Boundary behaviour of EHS}

Elliptical hollow sections are geometrically defined by the length of the two principal axes - the major (2a) and minor (2b) axes - as given by Eq. (2).

$$
\frac{x^{2}}{a^{2}}+\frac{y^{2}}{b^{2}}=1
$$

When both axes are of equal length, the section has an aspect ratio of unity and becomes a CHS, whilst when the minor axis length is negligible in comparison to the major axis length, the aspect ratio approaches infinity, and the case of two parallel plates results (Fig. 2). Therefore, the elastic buckling stress for an EHS should be a function of the aspect ratio and be bounded by the elastic buckling stress of a CHS (when the aspect 
ratio is equal to unity) and the elastic buckling stress of a flat plate (when the aspect ratio approaches infinity).

The elastic buckling stress of a CHS, found independently by Lorenz (1908), Timoshenko (1910) and Southwell (1914) [22], is given by Eq. (3).

$$
\sigma_{\mathrm{CHS}}=\frac{\mathrm{E}}{\sqrt{3\left(1-v^{2}\right)}} \frac{\mathrm{t}}{\mathrm{r}}
$$

where $\mathrm{r}$ and $\mathrm{t}$ are the radius of curvature and thickness of the CHS, respectively, and $\mathrm{E}$ and $v$ are the Young's modulus and Poisson's ratio of the material. The elastic local buckling stress of a CHS also depends on the length of the tube, due to the influence of the boundary conditions. The greater the length of the tube, the lower the buckling stress. The elastic buckling stress of a CHS, including length effects, is given in Eurocode 3 Part 1.6 [23] by Eq. (4).

$$
\sigma_{\mathrm{CHS}}=\frac{\mathrm{E}}{\sqrt{3\left(1-v^{2}\right)}} \frac{\mathrm{t}}{\mathrm{r}} \mathrm{C}_{\mathrm{x}}
$$

where $C_{x}$ is a coefficient defined by the relative length of the CHS: for medium-length cylinders $C_{x}=1$, whilst for short cylinders $C_{x}$ is greater than 1 and for long cylinders $C_{x}$ is less that 1. Based on the classifications proposed Eurocode 3 Part 1.6, all practical structural steel tubes would be regarded as either medium-length or long cylinders.

The elastic buckling stress of a compressed flat plate, found by Bryan (1891) [24], is given by Eq. (5).

$$
\sigma_{\text {Plate }}=\frac{K \pi^{2} E}{12\left(1-v^{2}\right)}\left(\frac{t}{w}\right)^{2}
$$


where $\mathrm{w}$ is the plate width, $\mathrm{t}$ is the plate thickness and $\mathrm{K}$ is a buckling coefficient dependant on the aspect ratio and the boundary conditions of the plate.

For EHS, much previous research has been based on the proposal of Kempner [9], which was later confirmed by Hutchinson [13], that the elastic buckling stress in compression may be taken as that of a CHS with a radius equal to the maximum radius of curvature in the elliptical section, given by Eq. (6).

$$
\mathrm{r}=\frac{\mathrm{a}^{2}}{\mathrm{~b}}
$$

The assumed elastic buckling stress of a compressed EHS is therefore given by Eq. (7).

$$
\sigma_{\mathrm{EHS}}^{\mathrm{K}}=\frac{\mathrm{E}}{\sqrt{3\left(1-v^{2}\right)}} \frac{\mathrm{t}}{\mathrm{a}^{2} / \mathrm{b}}
$$

In the initial design guidance for EHS developed by the steel producer, Corus [25], it was proposed that the equivalent radius for cross-section classification could be taken as Eq. (8), resulting in the elastic buckling stress of Eq. (9).

$$
\begin{aligned}
& r=a \sqrt{\frac{a}{b}} \\
& \sigma_{E H S}^{C}=\frac{E}{\sqrt{3\left(1-v^{2}\right)}} \frac{t}{a \sqrt{a / b}}
\end{aligned}
$$

For an EHS with an aspect ratio of unity, Eqs. (7) and (9) provide the same result, which is equal to that of Eq. (3) and that of Eq. (4) with $C_{x}=1$. Therefore, both equations fit the CHS bound. However, for an EHS of high aspect ratio, the elastic buckling stress of the EHS should tend to that of a flat plate, which neither Eq. (7) nor Eq. (9) predict. A formulation for the elastic buckling stress of an EHS that complies with both boundaries (CHS and plates) is therefore sought. Defining the equivalent 
diameter of an EHS D Eq,EHS $_{\text {as }}$ the diameter of a CHS with the same elastic buckling stress, and the relative equivalent diameter as the ratio between this equivalent diameter $\mathrm{D}_{\mathrm{Eq}, \mathrm{EHS}}$ and the major axis dimension (2a) of the EHS, leads to Eqs (10) and (11) for the CHS and plate boundaries, respectively:

$$
\begin{aligned}
& \frac{\mathrm{D}_{\mathrm{Eq}, \mathrm{EHS}}\left(\frac{\mathrm{a}}{\mathrm{b}}=1\right)}{2 \mathrm{a}}=1 \\
& \frac{\mathrm{D}_{\mathrm{Eq}, \mathrm{EHS}}\left(\frac{\mathrm{a}}{\mathrm{b}} \rightarrow \infty\right)}{2 \mathrm{a}}=\frac{8 \sqrt{3\left(1-v^{2}\right)}}{\mathrm{K} \pi^{2}} \frac{2 \mathrm{a}}{\mathrm{t}}
\end{aligned}
$$

From Eqs (10) and (11) it may be observed that the equivalent diameter is a function of both the aspect ratio $\mathrm{a} / \mathrm{b}$ and relative thickness $\mathrm{t} / 2 \mathrm{a}$. The relative equivalent diameters based on Kempner's assumption, Eq. (6), and Corus' proposal, Eq. (8), are given by Eqs (12) and (13) respectively; clearly neither of these expressions reflect the plate boundary given by Eq. (11).

$$
\begin{aligned}
& \frac{\mathrm{D}_{\mathrm{Eq}, \mathrm{EHS}}^{\mathrm{K}}}{2 \mathrm{a}}=\frac{\mathrm{a}}{\mathrm{b}} \\
& \frac{\mathrm{D}_{\mathrm{Eq}, \mathrm{EHS}}^{\mathrm{C}}}{2 \mathrm{a}}=\sqrt{\frac{\mathrm{a}}{\mathrm{b}}}
\end{aligned}
$$

\section{Simple analytical model representing the buckling of CHS, flat plates and EHS}

In this section, a simple analytical model that yields the exact classical elastic buckling stress of a CHS (Eq. (3)) as well as the wavelength of the longitudinal buckles is introduced. The proposed model is also applied to flat plates, obtaining an approximate solution for the elastic buckling stress, and finally the model is extended to EHS, providing an insight into their intermediate buckling response. 
Cite this paper as: Ruiz-Teran AM, Gardner L, 2008, Elastic buckling of elliptical tubes, Thin-Walled Structures, Vol:46, ISSN:0263-8231, Pages:1304-1318 [DOI: 10.1016/j.tws.2008.01.036]

\subsection{Simply model for representing the axis-symmetrical buckling of a compressed CHS}

When a CHS tube buckles in an axis-symmetrical mode, its deformed shape is such that all points at a given section have the same inwards or outwards displacement. Hence, knowledge of the displacements of all points along any longitudinal section allows the full deflected shape of the tube to be defined. In the buckled state (Fig. 3), the inclined nature of the longitudinal compressive load $\mathrm{P}$ results in a radial deviation force $\mathrm{F}_{\mathrm{d}}$ given by Eq. (14), where forces and displacements in the outward directions are positive.

$$
\mathrm{F}_{\mathrm{d}}=-\mathrm{Py}
$$

where $\mathrm{P}$ is the longitudinal compressive load acting on a differential element of area $(\mathrm{t} \times$ $d s), F_{d}$ is the radial deviation force acting on a unit area (ds $\left.\times d L\right), t$ is the thickness of the tube, ds and $\mathrm{dL}$ are defined in Fig. 3 and $\mathrm{y}$ is the function that describes the deflected shape of the tube.

This deviation force $F_{d}$ is resisted by two mechanisms: the flexural response of the longitudinal strips and the axial response of the transverse rings, both of which are illustrated in Fig. 3. The transverse rings with an outward displacement are in tension whereas those with an inward displacement are in compression. Buckling of a CHS tube can therefore be represented by a single longitudinal strip with a series of transverse springs corresponding to the rings. The stiffnesses of these two structural elements, the longitudinal strips $\mathrm{k}_{\text {strips }}$ and the transverse CHS rings $\mathrm{k}_{\mathrm{CHS}}$, are given by Eqs. (15) and (16), respectively. $\mathrm{k}_{\text {strips }}$ is a flexural stiffness per unit width, whilst $\mathrm{k}_{\mathrm{CHS}}$ is an axial stiffness per unit area.

$$
\mathrm{k}_{\text {strips }}=\frac{\mathrm{Et}^{3}}{12\left(1-v^{2}\right)}
$$




$$
\mathrm{k}_{\mathrm{CHS}}=\frac{\mathrm{Et}}{\mathrm{r}^{2}}
$$

The condition that the total deviation force must be resisted by both elements, gives rise to the differential equation that governs the buckling of a CHS tube in the axissymmetrical mode:

$-\mathrm{Py}^{\mathrm{II}}=\mathrm{k}_{\mathrm{CHS}} \mathrm{y}+\mathrm{k}_{\text {strips }} \mathrm{y}^{\mathrm{IV}}$

By setting $P=\sigma t$, substituting in the stiffness expressions from Eqs (15) and (16) and re-arranging, we obtain:

$$
\sigma y^{I I}+\frac{E}{r^{2}} y+\frac{E t^{2}}{12\left(1-v^{2}\right)} y^{I V}=0
$$

The solution to this homogeneous differential equation is of the form $y(x)=e^{z x}$ and the roots $\mathrm{z}$ are given by:

$\sigma z^{2}+\frac{E}{r^{2}}+\frac{E t^{2}}{12\left(1-v^{2}\right)} z^{4}=0$

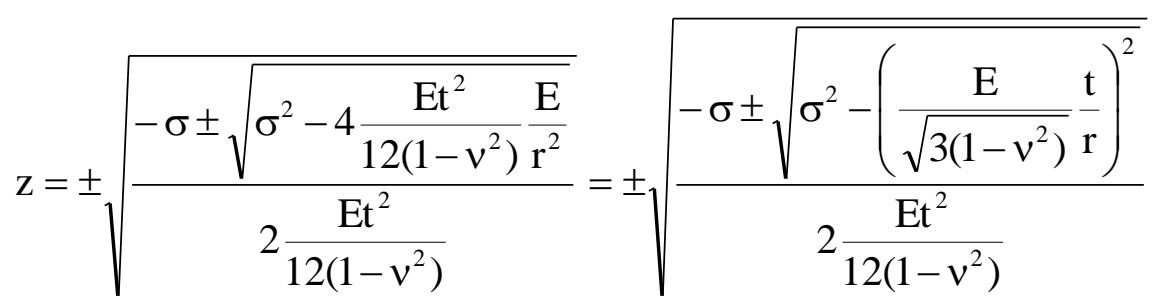

For an infinity long tube (i.e. when a tube buckles without being affected by the end boundary conditions), the solution must be of constant period and no hyperbolic functions can appear. Therefore, the square root in the numerator of Eq. (20) must be zero, and the solution $\mathrm{y}(\mathrm{x})$ is a linear combination of the functions $\sin (-\mathrm{zix})$ and $\cos (-$ zix). This square root becomes zero when the stress $\sigma$ is equal to the classical elastic 
buckling stress of a CHS $\sigma_{\mathrm{CHS}}$ given by Eq. (3). At this stress, the roots z from Eq. (20) are equal to:

$\mathrm{z}= \pm \frac{\sqrt[4]{12\left(1-v^{2}\right)}}{\sqrt{\mathrm{rt}}} \mathrm{i}$

And the half wavelength of the buckles $\mathrm{L}_{\mathrm{w}, \mathrm{CHS}}$ must satisfy:

$$
\mathrm{ziL}_{\mathrm{w}, \mathrm{CHS}}= \pm \pi
$$

leading to,

$$
\mathrm{L}_{\mathrm{w}, \mathrm{CHS}}=\frac{\pi}{\sqrt[4]{12\left(1-v^{2}\right)}} \sqrt{\mathrm{rt}} \approx 1.728 \sqrt{\mathrm{rt}}
$$

which is equal to the classical solution [22].

The model can be also used to identify when non-axis-symmetrical buckling modes (e.g. chessboard buckling) would be anticipated. The required radial load $\mathrm{q}_{\text {crit,ring }}$ to cause a ring to buckle with n waves may be determined from Eq. (24), as shown in [26].

$$
\mathrm{q}_{\text {crit }, \text { ring }}=\frac{\mathrm{E}}{12\left(1-v^{2}\right)}\left(\frac{\mathrm{t}}{\mathrm{r}}\right)^{3}\left(\mathrm{n}^{2}-1\right)
$$

As described earlier, when a compressed CHS tube buckles, part of the deviation force is resisted by the rings; these rings act in tension when their deflection is outwards and in compression when their deflection is inwards. Provided the rings are stiff enough to avoid buckling under the compressive deviation forces, the mode of buckling of the tube will be axis-symmetrical; if this is not the case, the buckling mode will be nonaxis-symmetrical. 
The elastic buckling stress of a CHS tube (given by Eq. (3)), and hence the inward deviation force, are proportional to $\mathrm{t} / \mathrm{r}$. However, the required radial load to cause ring buckling is proportional to $(\mathrm{t} / \mathrm{r})^{3}$ (see Eq. (24)). Therefore, when $\mathrm{t} / \mathrm{r}$ is large, resistance to ring buckling will be high in relation to the inward deviation force, and tube buckling will be in the axis-symmetrical mode. Conversely, when $t / r$ is small, a non-axissymmetrical mode would be expected, and furthermore, the smaller the $\mathrm{t} / \mathrm{r}$ ratio, the larger the number of circumferential buckles $\mathrm{n}$ that would result. It has already been established that stocky CHS tubes buckle in an axis-symmetrical mode whilst slender tubes exhibit a non-axis-symmetrical response [22], but the model described herein provides a simple explanation for this behaviour.

\subsection{Application of the proposed model to the buckling of flat plates under compression}

The previous model can be also applied to the buckling of flat plates despite there being no symmetry in the transverse direction (Fig. 4), as is the case in the buckling of a CHS, though the approach is a simplification of the problem. For the case of flat plates, there are two response mechanisms: the flexural response of the longitudinal strips and the flexural response of the transverse strips.

When a uniform load $\mathrm{q}$ is applied to a transverse strip (of flexural rigidity $\mathrm{EI}_{\text {Plate }}$ ) with fixed ends, the displacements $y_{\text {Plate }}$ along the length $\mathrm{x}$ are given by Eq. (25). The ends of the transverse strip are considered as fixed since this reflects the high rotational restraint provided by the stiff, high curvature regions of elliptical sections with high aspect ratios.

$$
\mathrm{y}_{\text {Plate }}(\mathrm{x})=\frac{\mathrm{qL}^{2} \mathrm{x}^{2}}{24 \mathrm{EI}_{\text {Plate }}}\left(1-2 \frac{\mathrm{x}}{\mathrm{L}}+\frac{\mathrm{x}^{2}}{\mathrm{~L}^{2}}\right)
$$


Since the stiffness of the transverse strips (defined as the ratio of the applied load to the deflection at a given section) is not uniform across the plate width $\mathrm{w}$, an average stiffness $\mathrm{k}_{\mathrm{Av} \text {,Plate }}$ can be obtained as:

$$
\mathrm{k}_{\text {Av }, \text { Plate }}=\frac{\mathrm{q}}{\frac{\int_{0}^{\mathrm{L}} \mathrm{y}_{\text {Plate }}(\mathrm{x}) \mathrm{dx}}{\mathrm{L}}}=\frac{720 \mathrm{EI}_{\text {Plate }}}{\mathrm{w}^{4}}=\frac{720 \mathrm{E} \frac{\mathrm{t}^{3}}{12\left(1-\mathrm{v}^{2}\right)}}{\mathrm{w}^{4}}=\frac{60 \mathrm{Et}^{3}}{\left(1-\mathrm{v}^{2}\right) \mathrm{w}^{4}}
$$

In this case the differential equation becomes:

$$
-\mathrm{Py}^{\mathrm{II}}=\mathrm{k}_{\mathrm{Av}, \text { Plate }} \mathrm{y}+\mathrm{k}_{\text {strips }} \mathrm{y}^{\mathrm{IV}}
$$

Following the same approach and assumptions as for CHS, the elastic buckling stress and buckling half-wavelength can be obtained as:

$$
\begin{aligned}
& \sigma_{\text {Approx,Plate }}=\frac{24 \sqrt{5} \mathrm{E}}{12\left(1-v^{2}\right)}\left(\frac{\mathrm{t}}{\mathrm{w}}\right)^{2} \\
& \mathrm{~L}_{\mathrm{w}, \text { Approx,Plate }}=\frac{\pi}{2 \sqrt[4]{45}} \mathrm{w} \approx 0.606 \mathrm{w}
\end{aligned}
$$

Considering the simplicity and approximate nature of the approach, the accuracy of the result is good, being only $22 \%$ below the classical elastic buckling stress of a flat plate with fixed edges, which may be obtained from Eq. (5) with $K=6.97$ [26]. To yield the exact solution, the stiffness of the transverse strips $\mathrm{k}_{\mathrm{Ex} \text {,plate }}$ would be:

$$
\mathrm{k}_{\mathrm{Ex}, \text { Plate }}=\frac{\mathrm{K}^{2} \pi^{4} \mathrm{Et}^{3}}{48\left(1-v^{2}\right) \mathrm{w}^{4}} \approx \frac{98.6 \mathrm{Et}^{3}}{\left(1-v^{2}\right) \mathrm{w}^{4}}
$$

And the buckling half-wavelength $\mathrm{L}_{\mathrm{w}, \text { Ex,Plate }}$ would be:

$$
\mathrm{L}_{\mathrm{w}, \mathrm{Ex}, \text { Plate }}=\sqrt{\frac{2}{\mathrm{~K}}} \mathrm{w} \approx 0.536 \mathrm{w}
$$




\subsection{Extension of the proposed model to the buckling of a compressed EHS}

Applying the simple model to the elastic buckling of an EHS in compression, the following differential equation is obtained:

$$
-\mathrm{Py}^{\mathrm{II}}=\mathrm{k}_{\mathrm{EHS}} \mathrm{y}+\mathrm{k}_{\text {strips }} \mathrm{y}^{\mathrm{IV}}
$$

where $\mathrm{k}_{\mathrm{EHS}}$ is the stiffness of the transverse EHS rings, which is bounded by Eq. (16) for CHS and Eq. (30) for flat plates.

Following the same approach as for CHS and flat plates, the elastic buckling stress and buckling half wavelengths of EHS can be obtained as:

$$
\begin{aligned}
& \sigma_{\text {Approx,EHS }}=\frac{2 \sqrt{\mathrm{k}_{\text {strips }} \mathrm{k}_{\mathrm{EHS}}}}{\mathrm{t}}=\sqrt{\frac{\mathrm{Et}}{3\left(1-v^{2}\right)} \mathrm{k}_{\mathrm{EHS}}} \\
& \mathrm{L}_{\mathrm{w}, \mathrm{EHS}}=\pi\left(\frac{\mathrm{k}_{\text {strips }}}{\mathrm{k}_{\mathrm{EHS}}}\right)^{0.25}=\pi\left(\frac{\mathrm{Et}^{3}}{12\left(1-v^{2}\right) \mathrm{k}_{\mathrm{EHS}}}\right)^{0.25}
\end{aligned}
$$

Eqs. (33) and (34) have been obtained by imposing a deflected shape for the buckled geometry in the simple model given by $\mathrm{y}(\mathrm{x})=\mathrm{A} \sin \left(\pi \mathrm{x} / \mathrm{L}_{\mathrm{w}, \mathrm{EHS}}\right)$. On this basis, the proportion of the total deviation force resisted by the transverse EHS rings can be obtained - the result is given in Eq. (35).

$$
\frac{\mathrm{k}_{\mathrm{EHS}} \mathrm{y}}{-\mathrm{Py}}=\frac{\mathrm{k}_{\mathrm{EHS}} \mathrm{A} \sin \left(\frac{\pi \mathrm{x}}{\mathrm{L}_{\mathrm{w}, \mathrm{EHS}}}\right)}{\sigma \mathrm{t}\left(\frac{\pi}{\mathrm{L}_{\mathrm{w}, \mathrm{EHS}}}\right)^{2} \sin \left(\frac{\pi \mathrm{x}}{\mathrm{L}_{\mathrm{w}, \mathrm{EHS}}}\right)}=\frac{\mathrm{k}_{\mathrm{EHS}}}{\sigma \mathrm{t}\left(\frac{\pi}{\mathrm{L}_{\mathrm{w}, \mathrm{EHS}}}\right)^{2}}=\frac{\mathrm{k}_{\mathrm{EHS}}}{2 \sqrt{\mathrm{k}_{\text {strips }} \mathrm{k}_{\mathrm{EHS}}} \sqrt{\frac{\mathrm{k}_{\mathrm{EHS}}}{\mathrm{k}_{\text {strips }}}}}=0.5
$$


The contribution of the transverse EHS rings is therefore equal to the contribution of the longitudinal strips, regardless of both the aspect ratio and the relative thickness. Hence, by eliminating $\mathrm{k}_{\mathrm{EHS}}$ from Eqs. (33) and (34), it is obtained that the elastic critical stress is given by:

$\sigma_{\text {Approx,EHS }}=2\left(\frac{\pi^{2} \mathrm{EI}}{\mathrm{tL}_{\mathrm{w}, \mathrm{EHS}}^{2}}\right)$

The elastic buckling stress of an EHS $\sigma_{\text {Approx,EHS }}$ may therefore be approximated as twice the Euler buckling stress of the longitudinal strips, with a buckling length equal to $\mathrm{L}_{\mathrm{w}, \mathrm{EHS}}$.

\section{Numerical modelling}

In order to investigate how the equivalent diameter of an EHS varies with aspect ratio $\mathrm{a} / \mathrm{b}$ and relative thickness $\mathrm{t} / 2 \mathrm{a}$, numerical solutions for elastic buckling loads for a set of EHS have been obtained by means of the finite element modelling package ABAQUS.

\subsection{Description of the models}

FE models were developed with a fixed major axis dimension of $400 \mathrm{~mm}$ and a fixed length of $1000 \mathrm{~mm}$. Nine variations of the minor axis dimension were taken: 400 (CHS), 300, 200, 135, 100, 65, 40, 20 and $0 \mathrm{~mm}$ (plate). Ten variations of thickness were considered: $40,32,25,20,16,10,8,5,2$ and $0.1 \mathrm{~mm}$. This provided aspect ratios a/b equal to $1.00,1.33,2.00,2.96,4.00,6.15,10.00,20.00$ and infinity, as well as relative thicknesses $\mathrm{t} / 2 \mathrm{a}$ equal to $0.100,0.080,0.0625,0.050,0.040,0.025,0.020$, $0.0125,0.005$ and 0.00025 (i.e. ranging between $1 / 10$ and 1/4000). The major and minor axis dimensions relate to the external surface of the EHS, and the ABAQUS 'offset' command [27] was used in order to define the centreline (mid-thickness) of the 
Cite this paper as: Ruiz-Teran AM, Gardner L, 2008, Elastic buckling of elliptical tubes, Thin-Walled

Structures, Vol:46, ISSN:0263-8231, Pages:1304-1318 [DOI: 10.1016/j.tws.2008.01.036]

sections. In all the models, there were 100 elements in the circumferential direction and 100 elements in the longitudinal direction, totalling 10000 elements. The basic element employed was a quadrilateral, stress/displacement shell element S4R, with reduced integration, a large-strain formulation and six degrees of freedom per node [27]. These elements allow transverse shear deformation and use thick shell theory when the shell thickness is large, but become discrete Kirchhoff thin shell elements as the thickness decreases. In order to assess the influence of shear deformation, some of the results were replicated using the STRI3 element, which is a triangular, stress/displacement shell element that employs thin shell theory. The elastic material properties of structural steel $\left(E=210000 \mathrm{~N} / \mathrm{mm}^{2}\right.$ and $\left.v=0.3\right)$ were employed for all models.

Boundary conditions were applied to model fixed ends. These were achieved by restraining all displacements and rotations at the base of the tubes, and all degrees of freedom except vertical displacement at the loaded end of the tubes, where compressive loading was uniformly distributed.

\subsection{Results from the numerical models}

The elastic buckling loads corresponding to the first mode of buckling obtained from the numerical models are presented in Table 1. The results are analysed in Section 6.

\section{Analysis of results}

\subsection{Comparison between FE and Kempner-based results}

The relative equivalent diameters obtained from the FE models and by means of Eq. (3) have been presented in Fig. 5, together with the relative equivalent diameters obtained from Kempner's assumption (Eq. (12)) and the from the Corus proposal for EHS 
Cite this paper as: Ruiz-Teran AM, Gardner L, 2008, Elastic buckling of elliptical tubes, Thin-Walled

Structures, Vol:46, ISSN:0263-8231, Pages:1304-1318 [DOI: 10.1016/j.tws.2008.01.036]

classification (Eq. (13)). Although the Corus proposal was not developed specifically to reflect the critical buckling stress of an EHS, it has been considered in this study for comparison purposes. The comparisons show that the equivalent diameter based on Kempner's assumption fits the numerical results well for very thin tubes (more slender than the practical range produced), whilst the equivalent diameter based on Corus's EHS classification fits the numerical results well for very stocky tubes (stockier than the practical range produced).

Figs 6 and 7 show the ratios between the elastic buckling stresses obtained based on the equivalent diameters of Kempner and Corus and that obtained from the FE models. Kempner's assumption consistently leads to conservative predictions, with errors between 14 and $24 \%$ for the current commercial range $(\mathrm{a} / \mathrm{b}=2$ and $\mathrm{t} / 2 \mathrm{a}$ ratios between 1/50 and 1/16) [25]. Corus' proposal results in unconservative predictions with errors between 7 and $21 \%$ for commercial geometries. The higher the aspect ratio, the greater the errors associated with both existing proposals.

\subsection{Interpretation of the buckling response mechanisms of compressed EHS tubes}

Both the aspect ratio $\mathrm{a} / \mathrm{b}$ and relative thickness $\mathrm{t} / 2 \mathrm{a}$ define the manner of buckling of an EHS. In Section 4.3, and in particular through Eq. (33), it was shown that the local buckling response of an EHS is governed by the stiffness of both the longitudinal and transverse elements. The longitudinal stiffness is simply defined by the flexural stiffness of the longitudinal strips since there is no curvature in the longitudinal direction. However, the transverse stiffness $\mathrm{k}_{\mathrm{EHS}}$ is influenced by both the flexural and membrane response of the transverse EHS rings. The longitudinal and transverse flexural stiffnesses are both proportional to the cube of the thickness (see Eqs (15), (26) and (30)), whereas the membrane stiffness is proportional to the thickness (see Eq. (16)). 
The stiffness of the transverse EHS rings, which was determined by means of substituting the numerically obtained elastic buckling stresses into Eq. (33), has been plotted in Fig. 8. The ratio between the total (flexural plus membrane) transverse stiffness of the EHS rings and the transverse flexural stiffness of a plate has been illustrated in Fig. 9. The results indicate that the smaller the relative thickness $t / 2 a$, the larger the ratio between the total transverse stiffness of the EHS and the transverse flexural stiffness of a plate, and therefore the higher the contribution of the membrane component. Also, as the aspect ratio $\mathrm{a} / \mathrm{b}$ of the section increases, the contribution of the membrane component reduces, and the total transverse stiffness of an EHS approaches the flexural stiffness of a flat plate (Eq. (30)). For high aspect ratios, the relative equivalent diameter reaches a plateau (Eq. (11) and Fig. 5), the level of which is governed by the relative thickness of the section. The higher the relative thickness, the smaller the aspect ratio required to reach plate-like behaviour (Figs 5 and 8).

The ratio of the transverse plate stiffness $\mathrm{k}_{\mathrm{Ex} \text {,plate }}$ to the stiffness of the transverse CHS rings $\mathrm{k}_{\mathrm{CHS}}$ can be obtained by substituting $\mathrm{r}=\mathrm{a}$ into Eq. (16) and $\mathrm{w}=2 \mathrm{a}$ into Eq. (30), resulting in:

$$
\frac{\mathrm{k}_{\text {Ex,Plates }}}{\mathrm{k}_{\mathrm{CHS}}}=\frac{24.65}{\left(1-\mathrm{v}^{2}\right)}\left(\frac{\mathrm{t}}{2 \mathrm{a}}\right)^{2}
$$

For the range of relative thickness considered in this study $(1 / 4000 \leq t / 2 a \leq 1 / 10)$, this ratio (Eq. (37)) is bounded between $1.7 \times 10^{-6}$ and 0.27 . For the commercial range of the relative thicknesses (approximately $1 / 50 \leq \mathrm{t} / 2 \mathrm{a} \leq 1 / 16$ ) [25], this ratio lies between 0.01 and 0.11, indicating that the transverse membrane stiffness of a CHS is more significant than the transverse flexural stiffness of a plate. 


\subsection{Half-wavelength of longitudinal buckles}

The half-wavelengths of the longitudinal buckles have been directly measured from the FE models and plotted in Fig. 10. These measurements are approximate, since they have been determined simply by means of counting the number of elements per buckling half-wave. Also, for the models with $t / 2 \mathrm{a}=1 / 4000$, results were influenced by the mesh density (i.e. the adopted mesh density was too coarse). Mesh refinement was found to alter the half-wavelength of the longitudinal buckles but not the elastic buckling stress. The results show that the higher the relative thickness $t / 2 a$, the longer the halfwavelengths of the longitudinal buckles (Fig. 10). All studied CHS buckled in non-axissymmetrical modes, in which the buckling half-wavelengths are longer than those with axis-symmetrical modes. For relative thicknesses less than or equal to $1 / 16$, there is a transition of buckling mode type from CHS-like modes to plate-like modes between the studied aspect ratios of 1 and 4/3, as described in Section 7. Beyond this transition point (i.e. a/b greater than approximately 4/3), the larger the aspect ratio, the longer the halfwavelengths of the longitudinal buckles (see Fig. 10), whilst for aspect ratios below the transition point, the reverse is true. For stocky sections with relative thickness larger than $1 / 16$, this transition point is found at higher aspect ratios (see Fig. 10). The plateau corresponding to the buckling half-wavelengths of flat plates with fixed edges (approximately equal to $0.70 \mathrm{w}$ ) may be clearly seen in Fig. 10.

The ratio between the half-wavelengths of the longitudinal buckles observed from the FE models and those obtained from the simple analytical model of Eq. (34), which is based on the assumption of an axis-symmetrical buckling mode, has been plotted in Fig. 11. Although the analytical model has been shown to accurately predict the elastic 
Cite this paper as: Ruiz-Teran AM, Gardner L, 2008, Elastic buckling of elliptical tubes, Thin-Walled

Structures, Vol:46, ISSN:0263-8231, Pages:1304-1318 [DOI: 10.1016/j.tws.2008.01.036]

buckling stress (Sections 4.1 and 4.2), Fig. 11 shows that the half-wavelength of the longitudinal buckles is less well predicted.

\subsection{The plate bound}

For high aspect ratios, the elastic buckling stress obtained from the FE models does not tend to the critical stress of a fixed plate given by Eq. (5), since shear deformation influences the results. In this sub-section, the level of influence of this effect is examined. Two cases have been investigated. In Case (1), shear deformation is considered (as in Section 5) and the length of the plate is varied with L/W ranging between 0.4 and 7.5. Case (2) is the same as Case (1) except that shear deformation is not considered. The results of Case (2) converge to the classical buckling stress given by Eq. (5) with $\mathrm{K}=6.97$ (for long plates). The influence of shear can be assessed by comparing the results of Cases (1) and (2), which have been plotted in Fig. 12 for L/w larger than 2. For ratios of $\mathrm{L} / \mathrm{w}$ less than 2 , the influence of the shear deformation depends on the length of the tubes, and the shorter the tubes, the higher the influence of the shear deformation. From Fig. 12 it may be observed that, as expected, the influence of shear is greater as the relative thickness increases and for low relative thickness, shear deformation has no effect. An expression for determining the elastic buckling stress for the plate bound, allowing for shear deformation (based on the proposed curves from Fig. 12) is given by Eq. (40).

\section{Transition between CHS and plate buckling modes}

For EHS with increasing aspect ratio $\mathrm{a} / \mathrm{b}$, there is a transition from CHS-like buckling modes to plate-like buckling modes. From Fig. 10, it may be observed that this transition is not gradual since the half-wavelengths of the longitudinal buckles change 
Cite this paper as: Ruiz-Teran AM, Gardner L, 2008, Elastic buckling of elliptical tubes, Thin-Walled Structures, Vol:46, ISSN:0263-8231, Pages:1304-1318 [DOI: 10.1016/j.tws.2008.01.036]

rapidly for aspect ratios close to unity and converge to the half-wavelength of the plate bound for high aspect ratios. In this section, the transition between the two responses CHS-like and plate-like buckling modes - is investigated. Two relative thicknesses $t / 2 \mathrm{a}$ are considered $-1 / 50$ and $1 / 16$ - representing the slenderness extremities of the practical range of produced EHS.

For EHS of any aspect ratio and relative thickness, both CHS-like and plate-like buckling modes are possible, though one or other may not appear until a number of higher buckling modes have been considered. CHS-like buckling modes are defined as those where the transverse waves spread all around the perimeter of the section (shown for EHS $400 \times 350 \times 8$ in Fig. 13(a)), whilst plate-like buckling modes are characterised by buckling waves occurring predominantly in the minor axis regions of the section (shown for the same EHS in Fig. 13(b)). For the example shown in Fig. 13, the lowest buckling mode is the plate-like mode (Fig. 13(b)), whilst the CHS-like response shown in Fig. 13(a) appears as a higher buckling mode.

In general, the lowest buckling modes for EHS with low aspect ratios are CHS-like modes, whereas the lowest buckling modes for EHS with high aspect ratios are platelike modes. Fig. 14 illustrates the transitional behaviour with aspect ratio for the two relative thicknesses considered. The transition point is defined as the aspect ratio at which the lowest buckling mode changes from a CHS-like response to a plate-like response, at which point there is no sudden variation in buckling load, but the buckling wavelength alters significantly due to the difference in mode. From Fig. 14, it may be seen that these points occur at aspect ratios of approximately 1.05 for $t / 2 \mathrm{a}=1 / 50$ and 1.19 for $\mathrm{t} / 2 \mathrm{a}=1 / 16$, and it may be inferred that the smaller the relative thickness, the 
Cite this paper as: Ruiz-Teran AM, Gardner L, 2008, Elastic buckling of elliptical tubes, Thin-Walled

Structures, Vol:46, ISSN:0263-8231, Pages:1304-1318 [DOI: 10.1016/j.tws.2008.01.036]

lower the aspect ratio of the transition point. For the practical range of relative thicknesses of EHS, the transition point occurs at an aspect ratio of less than 1.2.

\section{Length effects}

The local elastic buckling loads of CHS and EHS are influenced by member length. Eurocode 3 Part 1-6 [23] accounts for length effects in CHS through the $\mathrm{C}_{\mathrm{x}}$ factor that appears in Eq. (4). For medium and long CHS tubes, $\mathrm{C}_{\mathrm{x}}$ is given by Eq. (38), where the $2 \mathrm{a}$ is the diameter of the CHS and L is the length.

$$
C_{x}=1+\frac{0.2}{6}\left(1-4 \sqrt{2} \frac{L}{2 a} \sqrt{\frac{t}{2 a}}\right) \leq 1
$$

In order to investigate length effects in EHS, models of three times the length $(\mathrm{L} / 2 \mathrm{a}=$ 7.5) of those studied in Section 5 have been analysed. The elastic buckling loads for three aspect ratios $(1.00,1.33$ and 2.00) have been presented in Table 2. In Fig. 15, the buckling loads of the shorter EHS $(\mathrm{L} / 2 \mathrm{a}=2.5)$ have been normalised by those for the longer EHS $(\mathrm{L} / 2 \mathrm{a}=7.5)$. A solid line representing the ratio of $\mathrm{C}_{\mathrm{x}}$ factors for the two lengths (i.e. $\mathrm{C}_{\mathrm{x}}$ for $\mathrm{L} / 2 \mathrm{a}=2.5$ divided by $\mathrm{C}_{\mathrm{x}}$ for $\mathrm{L} / 2 \mathrm{a}=7.5$ ) as given by Eurocode 3 Part 1.6 has been added to Fig. 15. Within the commercial range, this line may be seen to closely match the FE results for $\mathrm{a} / \mathrm{b}=1$. Two further dashed lines, representing the proposals of the authors for $\mathrm{a} / \mathrm{b}=1.33$ and 2.00 have also been added to Fig. 15. The results clearly indicate that the higher the aspect ratio, the smaller the effect of length on the elastic buckling stress. The proposals for $\mathrm{C}_{\mathrm{x}, \mathrm{EHS}}$ factors for all aspect ratios, based on the $\mathrm{C}_{\mathrm{x}}$ factors for CHS from Eurocode 3 Part 1.6, are given by Eq. (44). 


\section{Proposed formulations}

It is proposed that the elastic buckling stress of an EHS under compression may be determined from Eq. (39).

$$
\sigma_{\mathrm{EHS}}=\frac{\mathrm{E}}{\sqrt{3\left(1-v^{2}\right)}} \frac{2 \mathrm{t}}{\mathrm{D}_{\mathrm{Eq}, \mathrm{EHS}}} \mathrm{C}_{\mathrm{x}, \mathrm{EHS}}>\sigma_{\text {Plate }}^{*}
$$

where $\sigma^{*}$ Plate is the elastic buckling stress of a flat plate with the same boundary conditions at the loaded ends as the EHS and taking into consideration shear deformation (i.e. Mindlin plates [28,29]). This may be approximated by:

$$
\sigma_{\text {Plate }}^{*}=\frac{K^{*} \pi^{2} E}{12\left(1-v^{2}\right)}\left(\frac{t}{w}\right)^{2} \varphi_{\text {SD }}
$$

where $\mathrm{w}$ is the width of the plate $(\mathrm{w}=2 \mathrm{a}), \mathrm{K}^{*}$ is the buckling coefficient for all plate edges fixed [26] that can be approximated from Eq. (41), and $\varphi_{\mathrm{SD}}$ is a reduction factor that accounts for shear deformation (Eq. (42)). $\mathrm{K}^{*}$ may be conservatively taken as 6.97 .

$$
\begin{gathered}
\mathrm{K}^{*}=\left\{\begin{array}{cc}
6.97+0.03\left(5-\frac{\mathrm{L}}{\mathrm{w}}\right)^{3} & 2 \leq \frac{\mathrm{L}}{\mathrm{w}}<5 \\
6.97 & 5 \leq \frac{\mathrm{L}}{\mathrm{w}}
\end{array}\right. \\
\varphi_{\mathrm{SD}}=1-16\left(\frac{\mathrm{t}}{\mathrm{w}}\right)^{2}
\end{gathered}
$$

Consequently, the relative equivalent diameter for the plate boundary, which was given by Eq. (11), can be improved by including the influence of shear deformation, as given by:

$$
\frac{\mathrm{D}_{\mathrm{Eq}, \text { Plate }}}{2 \mathrm{a}}=\frac{8 \sqrt{3\left(1-v^{2}\right)}}{\mathrm{K}^{*} \pi^{2}} \frac{2 \mathrm{a}}{\mathrm{t}} \frac{1}{\varphi_{\mathrm{SD}}}
$$


The length effect factor $\mathrm{C}_{\mathrm{x}, \mathrm{EHS}}$ for use in Eq. (39) was analysed in Section 8, and may be determined from Eq. (44) based on the $\mathrm{C}_{\mathrm{x}}$ factor given by Eurocode 3 Part 1-6 for CHS (Eq. (38)).

$$
\mathrm{C}_{\mathrm{x}, \mathrm{EHS}}=\left\{\begin{array}{cc}
1-\left(1-\mathrm{C}_{\mathrm{x}}\right)\left(\frac{2.5-\frac{\mathrm{a}}{\mathrm{b}}}{1.5}\right)^{2} & \mathrm{a} / \mathrm{b}<2.5 \\
1 & \mathrm{a} / \mathrm{b} \geq 2.5
\end{array}\right.
$$

The proposal for the equivalent relative diameter arises from consideration of the results shown in Fig. 5, where it may be observed that (1) for small aspect ratios, the relative equivalent diameter is approximately linearly proportional to the aspect ratio, and that (2) the smaller the relative thickness, the higher the slope of the lines. Therefore, a simple expression with the following form is proposed:

$$
\frac{\mathrm{D}_{\mathrm{Eq}, \mathrm{EHS}}}{2 \mathrm{a}}=1+\mathrm{f}\left(\frac{\mathrm{a}}{\mathrm{b}}-1\right)<\frac{\mathrm{D}_{\mathrm{Eq}, \text { Plate }}}{2 \mathrm{a}}
$$

where the $\mathrm{f}$ values are obtained from Eq. (46), which provides a conservative approximation of the results of the FE models (see Fig. 16).

$$
f=1-2.3\left(\frac{t}{2 a}\right)^{0.6}
$$

Elastic buckling stresses for EHS have been estimated using three different approaches: (1) the authors' proposal given by Eqs (39) to (46), (2) Kempner's assumption (Eq. (12)) including the length effect (Eq. (44)), and (3) a modified version of Kempner's approach (Eq. (12)) that includes the length effect (Eq. (44)), but is also bounded by the plate buckling expression of Eq. (40). The predicted elastic buckling stresses given by the three different approaches have been compared with the numerically generated results in Fig. 17. 
For the full range of aspect ratios (Fig. 17 (a)), the proposed formula yields maximum disparities from the numerical results of less than $17 \%$, which are markedly lower than the $90 \%$ obtained from Kempner's assumption. Furthermore, the proposed formula (as with Kempner's approach) consistently provides lower bound solutions. The modified Kempner approach whereby the plate bound is also considered in evaluating the elastic buckling stress yields disparities of up to $33 \%$, representing a marked improvement over Kempner's original approach. For the more practical range of geometries $(\mathrm{a} / \mathrm{b}<4$ and t/2a $<1 / 16$ ) (Fig. 17 (b)), the proposed formula yields maximum disparities from the numerical results of less than $13 \%$, compared to $39 \%$ and $31 \%$ for the original and modified Kempner approaches, respectively. For slender sections within the practical range of geometries $(\mathrm{a} / \mathrm{b}<4$ and $\mathrm{t} / 2 \mathrm{a}<1 / 50)$ (Fig. 17 (c)), which are most susceptible to local buckling, the proposed formula yields maximum disparities from the numerical results of less than $6 \%$, compared to the $22 \%$ obtained from the original and modified Kempner approaches. The proposed approach for determining elastic buckling loads for compressed EHS is simple and yields accurate and conservative results over a wide range of geometries.

\section{Application of the findings to cross-section classification}

Cross-section classification represents a fundamental feature of metallic structural design, whereby cross-sections are placed into discrete behavioural classes based on their local buckling response. The two keys features of the classification system are the slenderness parameters (measures of local cross-sectional slenderness) and slenderness limits (to mark the boundaries between the classes). For CHS, the basic slenderness parameter adopted in Eurocode 3 is $\mathrm{D} / \mathrm{t} \varepsilon^{2}$, where $\mathrm{D}$ and $\mathrm{t}$ are the diameter and thickness of the CHS, respectively and $\varepsilon=\left(235 / \sigma_{\mathrm{y}}\right)^{0.5}$ where $\sigma_{\mathrm{y}}$ is the material yield strength. For 
the cross-section classification of EHS, it has recently been proposed [7] that the slenderness parameter for compression be taken as $D_{e} / t \varepsilon^{2}$, where $D_{e}$ is defined on the basis of Kempner's assumption as $2 \mathrm{a}^{2} / \mathrm{b}$. This has been found to yield conservative results in comparison to CHS, and therefore allows the CHS slenderness limits to also be applied to EHS. However, for greater structural efficiency, and to reduce the need for the lengthy calculations associated with slender (Class 4) cross-sections, it is proposed herein that $D_{e}$ be taken equal to $D_{E q, E H S}$ determined from Eq. (45), with the coefficient $f$ from Eq. (46).

A comparison of CHS and EHS test data in compression is shown in Fig. 18. For the EHS, the results are plotted on the basis of the Kempner equivalent diameter $\left(2 \mathrm{a}^{2} / \mathrm{b}\right)$ and the proposed equivalent diameter (from Eq. (45)). Regression curves have been added for the three data sets. These clearly indicate that both slenderness parameters for EHS are conservative in comparison to $\mathrm{CHS}$, but the proposed equivalent diameter yields closer agreement between the two section types, and is therefore more accurate and appropriate for design. On this basis, it is recommended that EHS may be classified in compression using CHS slenderness limits and the equivalent diameter from Eq. (45).

\section{Conclusions}

Tubular members of elliptical cross-section have recently been introduced into the construction market, offering a new alternative to structural engineers and architects. As part of the development of structural design rules for EHS, this paper has focused on both the explanation and the accurate prediction of their elastic buckling response, being intermediate between that of circular sections and flat plates. The transition between these two boundaries is dependant upon both the aspect ratio and relative thickness of the section; a simple analytical model has been developed to explain how these two 
Cite this paper as: Ruiz-Teran AM, Gardner L, 2008, Elastic buckling of elliptical tubes, Thin-Walled

Structures, Vol:46, ISSN:0263-8231, Pages:1304-1318 [DOI: 10.1016/j.tws.2008.01.036]

parameters influence the longitudinal and transverse stiffnesses of the section and thereby control the structural behaviour (buckling mode and wavelength) and elastic buckling stress of elliptical tubes. Based on numerical results, a simple yet accurate approach to determine the elastic buckling stress of compressed EHS has been proposed. This approach offers significant improvements in the prediction of elastic buckling stresses over existing approaches. The proposed formula for the equivalent diameter has also been incorporated into a slenderness parameter for the cross-section classification of EHS. The validity and benefit of this inclusion have been shown through comparisons with available test results.

\section{Acknowledgments}

The authors are grateful to the Spanish Ministry of Education and the University of Castilla-La Mancha for providing fellowship funding for the first author's academic visits to Imperial College London.

\section{References}

[1] Ryall MJ. Britannia bridge: from concept to construction. Proc. Inst. Civ. Engrs, Civ. Engng 1999; 132(2-3): 132-143.

[2] Bate SCC, Campbell P, Dunican PT, Happold E, Harley-Haddow T, Mainstone RJ, Morgan CD, Newby F, Sutherland RJM.. Structural Engineering. Two centuries of British achievement. Kent, United Kingdom: Tarot Print Limited, 1983.

[3] Binding J. Brunel's Royal Albert Bridge: A Study of the Design and Construction of His 'Gateway to Cornwall' at Saltash. Cornwall, UK: Twelveheads Press, 1997.

[4] McKechnie S. Terminal 5. London Heathrow: The main terminal building envelope. The Arup Journal 2006; 41(2): 36-43. 
Cite this paper as: Ruiz-Teran AM, Gardner L, 2008, Elastic buckling of elliptical tubes, Thin-Walled

Structures, Vol:46, ISSN:0263-8231, Pages:1304-1318 [DOI: 10.1016/j.tws.2008.01.036]

[5] Viñuela L, Martinez J. Steel structure and prestressed façade of the new Terminal Building. Hormigón y Acero 2006; 239(1): 71-84.

[6] Corus. Celsius 355® Ovals. Structural \& Conveyance Business. Internet: < http://www.corusbouw.nl/file_source/StaticFiles/Construction/Corusbouw/CT28-

Celsius_355_Oval_01-07-03.pdf > [2 Jul 2007], 2006

[7] Gardner L, Chan TM. Cross-section classification of elliptical hollow sections. Journal of Steel and Composite Structures 2007; 7(3): 185-200.

[8] Marguerre K. Stability of the cylindrical shell of variable curvature. Technical Memorandum 1302, National Advisory Committee for Aeronautics, Washington, 1951

[9] Kempner J. Some results on buckling and postbuckling of cylindrical shells. Collected papers on instability of shell structures. NASA TND-1510, Dec 1962: 173186. NASA, Polytechnic Institute of Brooklyn, Brooklyn 1962

[10] Feinstein G, Chen YN, Kempner J. Buckling of Clamped oval cylindrical shells under axial loads. American Institute of Aeronautic and Astronautic Journal 1971; 9(9): $1733-1738$

[11] Kempner J, Chen YN. Large deflections of an axially compressed oval cylindrical shell. In: 11th International Congress of applied mechanics. Munich- Berlin: SpringerVerlag; 1964. p. 299-305.

[12] Kempner J, Chen YN. Buckling and Post-buckling of an axially compressed oval cylindrical shell. PIBAL Report No 917, Polytechnic Institute of Brooklyn, Brooklyn, 1966. Also In: $17^{\text {th }}$ Anniversary Symposium on Shells to honour Lloyd Hamilton Donnell. Houston, Texas.

[13] Hutchinson JW. Buckling and initial post-buckling behaviour of oval cylindrical shells under axial compression. Journal of Applied Mechanics, March 1968: 66-72. 
Cite this paper as: Ruiz-Teran AM, Gardner L, 2008, Elastic buckling of elliptical tubes, Thin-Walled Structures, Vol:46, ISSN:0263-8231, Pages:1304-1318 [DOI: 10.1016/j.tws.2008.01.036]

[14] Kempner J, Chen YN. Post-buckling of an axially compressed oval cylindrical shell. In: $12^{\text {th }}$ International Congress of Applied Mechanics. Stanford University, 1968. p. $246-256$

[15] Tennyson RC, Booton M, Caswell RD. Buckling of imperfect elliptical cylindrical shells under axial compression. American Institute of Aeronautic and Astronautic Journal 1971; 9(2): 250-255

[16] Tvergaard V. Buckling of elastic-plastic oval cylindrical shells under axial compression. International Journal of Solid and Structures 1976; 12: 683-691.

[17] Gardner L. Structural behaviour of oval hollow sections. International Journal of Advanced Steel Construction 2005; 1(2): 26-50.

[18] Gardner L, Ministro A. Structural steel oval hollow sections. The Structural Engineer 2005; 83(21): 32-36.

[19] Chan TM, Gardner L. Compressive resistance of hot-rolled elliptical hollow sections. Engineering Structures (in press).

[20] Chan TM, Gardner L. Bending strength of hot-rolled elliptical hollow sections. Journal of Constructional Steel Research (submitted).

[21] Zhu, Y. and Wilkinson, T. (2006). Finite element analysis of structural steel elliptical hollow sections in pure compression. 11th International Symposium on Tubular Structures - ISTS11. 31 August - 2 September 2006, Quebec City, Canada. pp. 179-186.

[22] Rotter JM. Buckling of thin metal shells. London: Spon Press., 2004.

[23] EN 1993-1-6. Eurocode 3: Design of steel structures. Part 1.6: General rules. Strength and stability of shell structures. Brussels: European Committee for standardisation, 2007 
Cite this paper as: Ruiz-Teran AM, Gardner L, 2008, Elastic buckling of elliptical tubes, Thin-Walled Structures, Vol:46, ISSN:0263-8231, Pages:1304-1318 [DOI: 10.1016/j.tws.2008.01.036]

[24] Timoshenko SP, Gere JM. Theory of elastic stability. Singapore: McGraw-Hill, 1961.

[25] Corus. (2004). Celsius 355® Ovals - Size and resistances. Structural \& Conveyance Business.

[26] Allen HG, Bulson PS. Background to buckling. Berkshire, UK: McGraw-Hill, 1980.

[27] ABAQUS. (2006). ABAQUS/ Standard User's Manual Volumes I-III and ABAQUS CAE Manual. Version 6.6. Hibbitt, Karlsson and Sorensen, Inc. Pawtucket, USA.

[28] Dawe DJ, Roufaeil OL. Buckling of rectangular Mindlin plates. Computers \& Structures 1982; 15(4): 461-471

[29] Wang CM, Xiang V, Kitipornchai S, Liew KM. Buckling solutions for Mindlin plates of various shapes. Engineering Structures 1994; 16(2): 119-127. 
Cite this paper as: Ruiz-Teran AM, Gardner L, 2008, Elastic buckling of elliptical tubes, Thin-Walled Structures, Vol:46, ISSN:0263-8231, Pages:1304-1318 [DOI: 10.1016/j.tws.2008.01.036]

\section{Tables}

Table 1. Results of models with $\mathrm{L} / 2 \mathrm{a}=2.5$. Elastic buckling loads.

Table 2. Results of models with $\mathrm{L} / 2 \mathrm{a}=7.5$. Elastic buckling loads. 
Cite this paper as: Ruiz-Teran AM, Gardner L, 2008, Elastic buckling of elliptical tubes, Thin-Walled Structures, Vol:46, ISSN:0263-8231, Pages:1304-1318 [DOI: 10.1016/j.tws.2008.01.036]

Table 1: Results of models with $\mathrm{L} / 2 \mathrm{a}=2.5$. Elastic buckling loads.

\begin{tabular}{|c|c|c|c|c|c|c|c|c|c|c|c|}
\hline \multicolumn{2}{|c|}{ Major and minor axis } & \multicolumn{10}{|c|}{ Elastic buckling loads of the modelled EHS (MN) } \\
\hline 400 & 300 & $5.44 \times 10^{-3}$ & 2.19 & 14.00 & 36.50 & 57.62 & 151.35 & 239.44 & 375.57 & 588.40 & 898.21 \\
\hline 400 & 200 & $3.20 \times 10^{-3}$ & 1.31 & 8.49 & 22.44 & 35.68 & 95.37 & 150.31 & 232.76 & 386.68 & 628.64 \\
\hline 400 & 100 & $1.42 \times 10^{-3}$ & 0.60 & 4.02 & 10.82 & 17.01 & 45.29 & 76.03 & 131.48 & 246.72 & 439.65 \\
\hline 400 & 65 & $8.79 \times 10^{-4}$ & 0.38 & 2.61 & 6.72 & 10.96 & 34.59 & 62.28 & 113.85 & 223.38 & 409.10 \\
\hline 400 & 40 & $5.40 \times 10^{-4}$ & 0.24 & 1.61 & 4.78 & 8.49 & 30.62 & 57.41 & 108.02 & 216.55 & 401.48 \\
\hline
\end{tabular}


Cite this paper as: Ruiz-Teran AM, Gardner L, 2008, Elastic buckling of elliptical tubes, Thin-Walled Structures, Vol:46, ISSN:0263-8231, Pages:1304-1318 [DOI: 10.1016/j.tws.2008.01.036]

Table 2: Results of models with $\mathrm{L} / 2 \mathrm{a}=7.5$. Elastic buckling loads.

\begin{tabular}{|c|c|c|c|c|c|c|c|c|c|c|}
\hline \multicolumn{2}{|c|}{ Major and minor axis } & \multicolumn{9}{|c|}{ Elastic buckling loads of the modelled EHS (MN) } \\
\hline $2 \mathrm{a}(\mathrm{mm})$ & $2 \mathrm{~b}(\mathrm{~mm})$ & $\mathrm{t}=2 \mathrm{~mm}$ & $\mathrm{t}=5 \mathrm{~mm}$ & $\mathrm{t}=8 \mathrm{~mm}$ & $\mathrm{t}=10 \mathrm{~mm}$ & $\mathrm{t}=16 \mathrm{~mm}$ & $\mathrm{t}=20 \mathrm{~mm}$ & $\mathrm{t}=25 \mathrm{~mm}$ & $\mathrm{t}=32 \mathrm{~mm}$ & $\mathrm{t}=40 \mathrm{~mm}$ \\
\hline 400 & 400 & 3.11 & 18.64 & 44.80 & 64.25 & 152.16 & 229.21 & 351.04 & 570.97 & 894.22 \\
\hline 400 & 300 & 2.19 & 13.92 & 36.23 & 55.24 & 132.18 & 204.49 & 315.86 & 518.98 & 820.66 \\
\hline 400 & 200 & 1.30 & 8.44 & 22.28 & 35.44 & 92.40 & 143.55 & 225.04 & 374.78 & 605.71 \\
\hline
\end{tabular}


Cite this paper as: Ruiz-Teran AM, Gardner L, 2008, Elastic buckling of elliptical tubes, Thin-Walled Structures, Vol:46, ISSN:0263-8231, Pages:1304-1318 [DOI: 10.1016/j.tws.2008.01.036]

a)

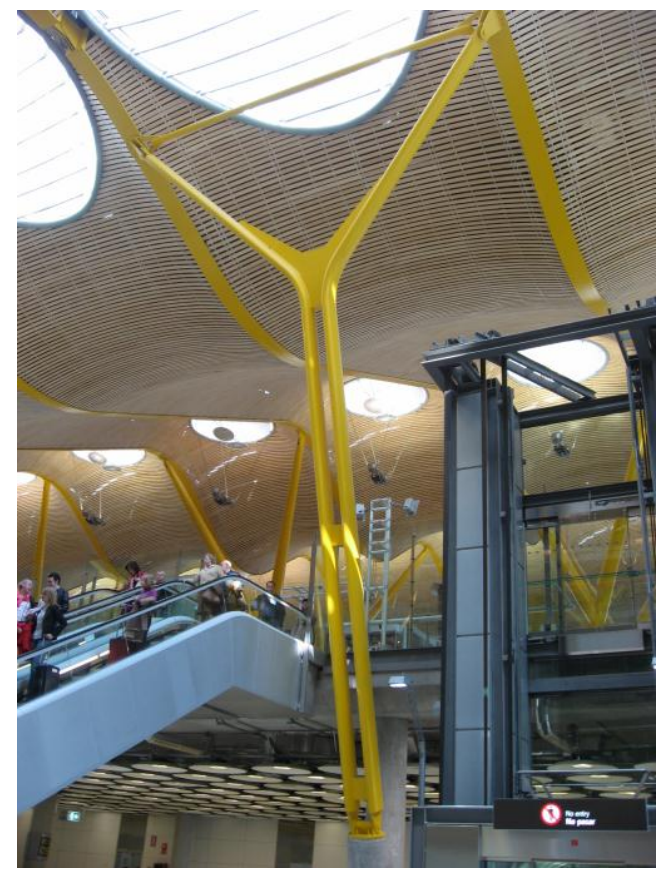

b)

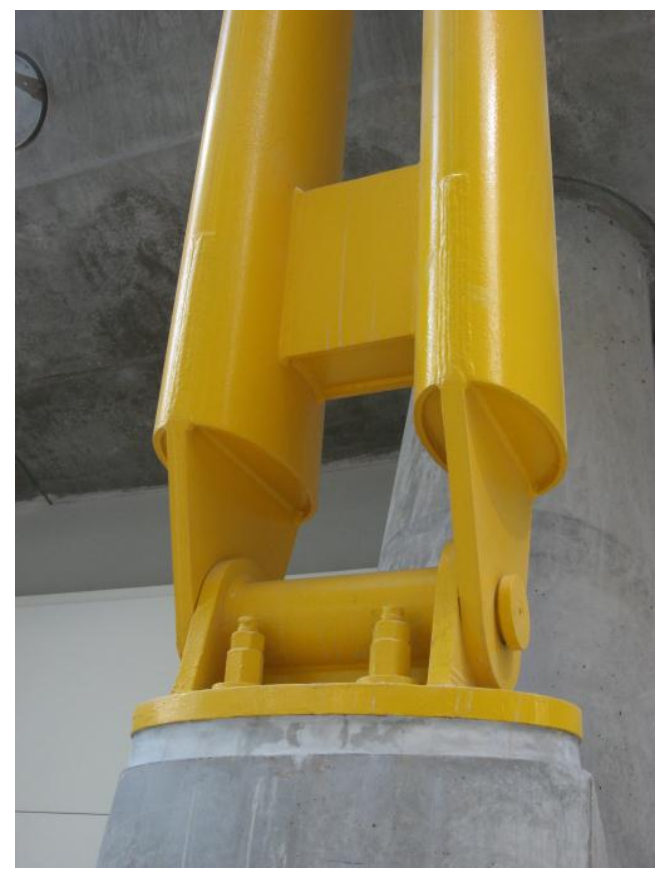

Fig. 1. Terminal 4 of Barajas Airport in Madrid, Spain [5]. a) EHS columns to support the roof structure and b) Connection detail at base of columns 
Cite this paper as: Ruiz-Teran AM, Gardner L, 2008, Elastic buckling of elliptical tubes, Thin-Walled Structures, Vol:46, ISSN:0263-8231, Pages:1304-1318 [DOI: 10.1016/j.tws.2008.01.036]

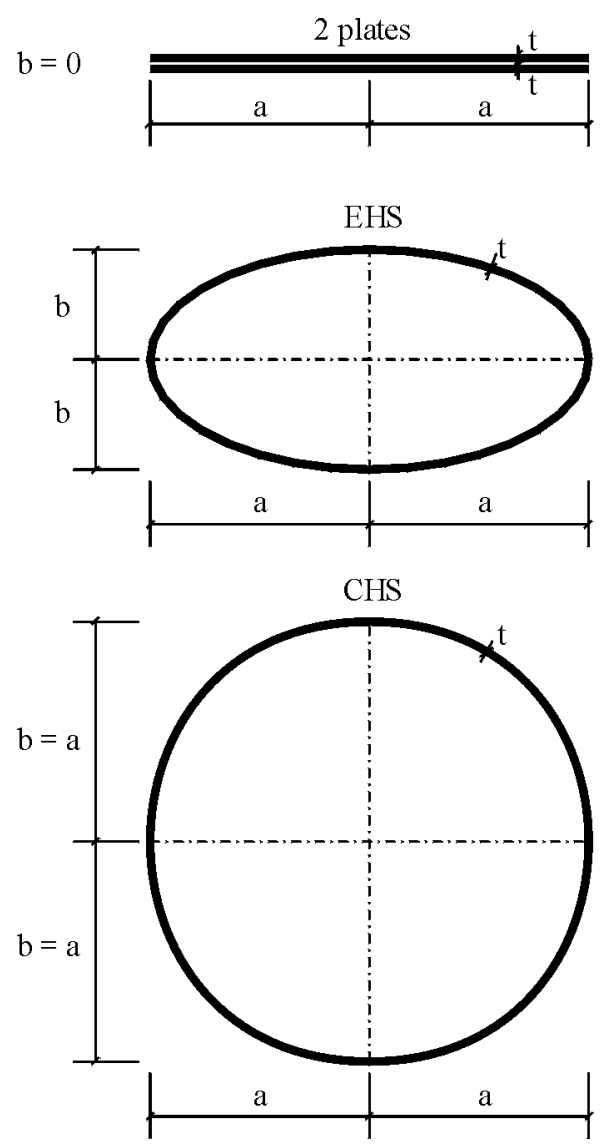

Fig. 2: Transition between plate, EHS and CHS geometry 
Cite this paper as: Ruiz-Teran AM, Gardner L, 2008, Elastic buckling of elliptical tubes, Thin-Walled Structures, Vol:46, ISSN:0263-8231, Pages:1304-1318 [DOI: 10.1016/j.tws.2008.01.036]

a)

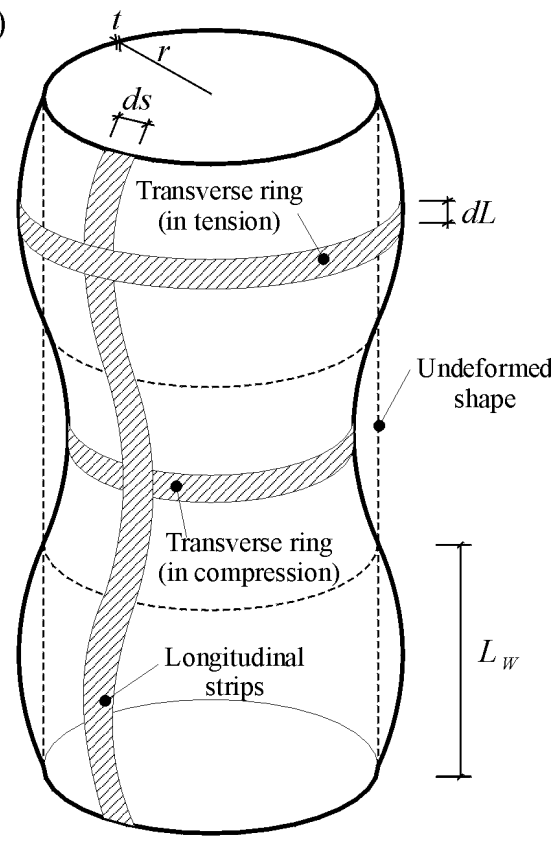

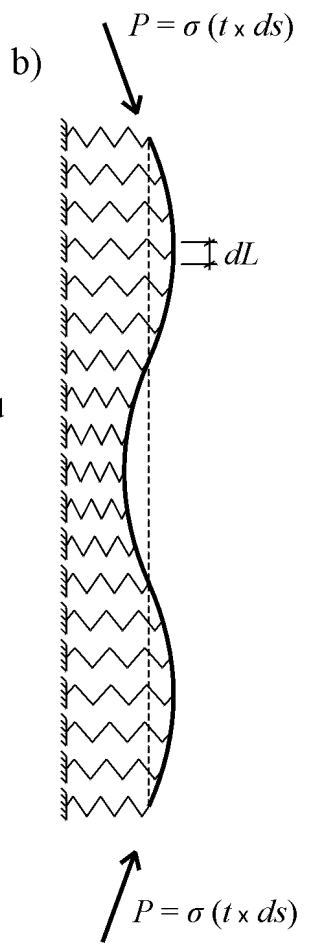

c)
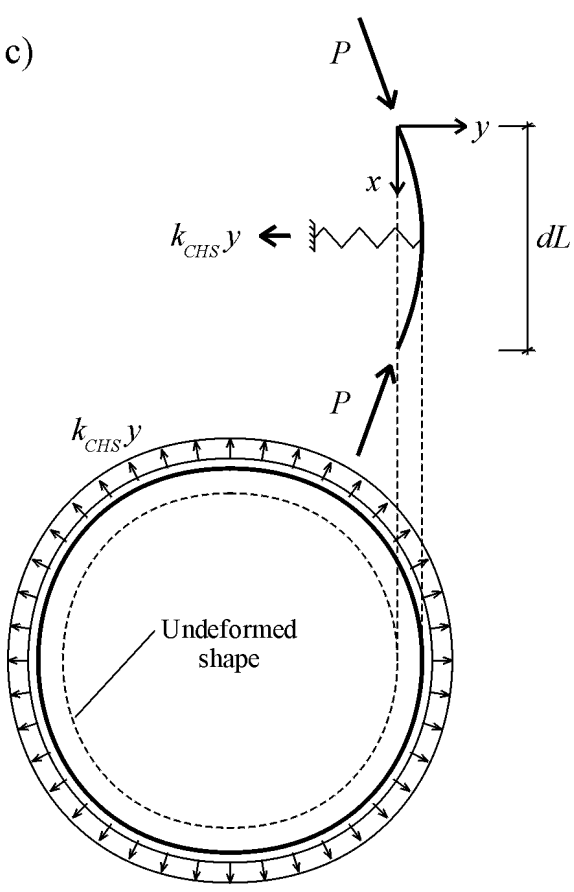

Fig. 3: Simple model for the axis-symmetrical buckling of CHS. a) Elements

contributing to the structural response, b) Simple model, c) Link between longitudinal and transverse elements 
Cite this paper as: Ruiz-Teran AM, Gardner L, 2008, Elastic buckling of elliptical tubes, Thin-Walled Structures, Vol:46, ISSN:0263-8231, Pages:1304-1318 [DOI: 10.1016/j.tws.2008.01.036]

a)

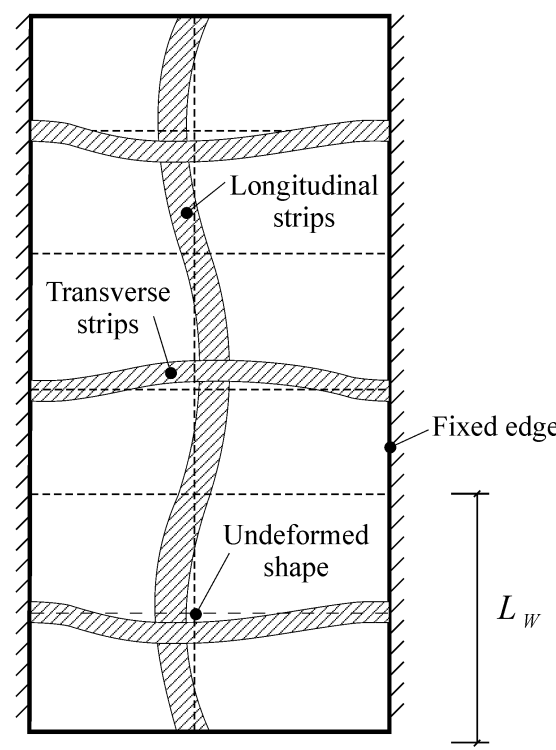

b)

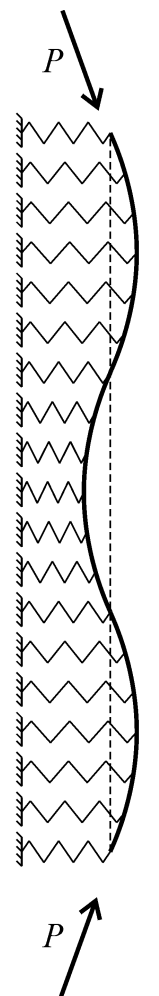

c)

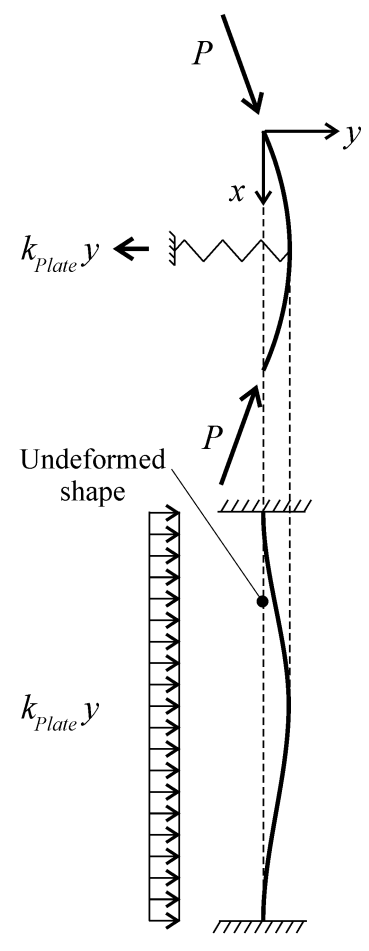

Fig. 4: Simple model for the buckling of plates with fixed edges: a) Elements contributing to the structural response, b) Simple model, c) Link between longitudinal and transverse elements 


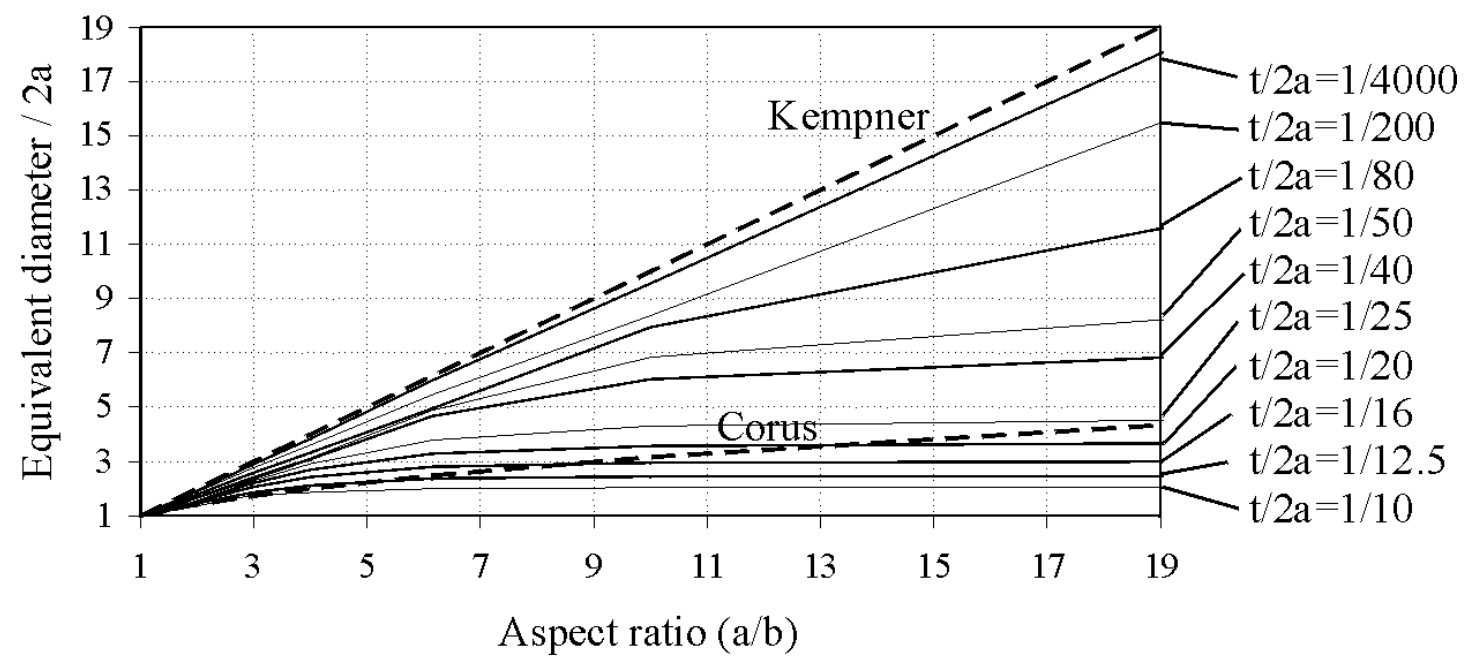

Fig. 5. Relative equivalent diameters versus aspect ratio 
Cite this paper as: Ruiz-Teran AM, Gardner L, 2008, Elastic buckling of elliptical tubes, Thin-Walled Structures, Vol:46, ISSN:0263-8231, Pages:1304-1318 [DOI: 10.1016/j.tws.2008.01.036]

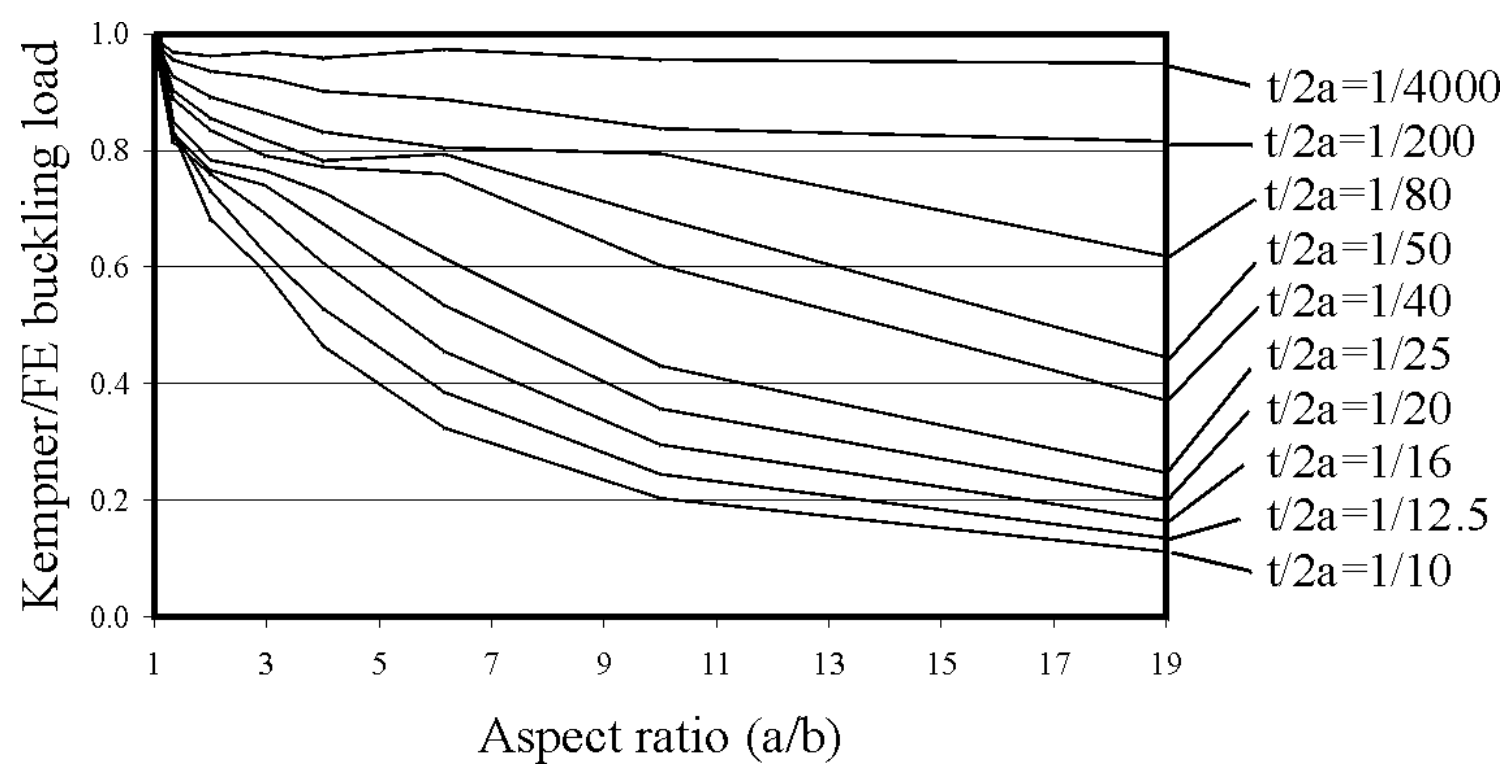

Fig. 6. Ratio between the elastic buckling load obtained with Kempner assumption and that obtained by FE versus the aspect ratio of the EHS 
Cite this paper as: Ruiz-Teran AM, Gardner L, 2008, Elastic buckling of elliptical tubes, Thin-Walled Structures, Vol:46, ISSN:0263-8231, Pages:1304-1318 [DOI: 10.1016/j.tws.2008.01.036]

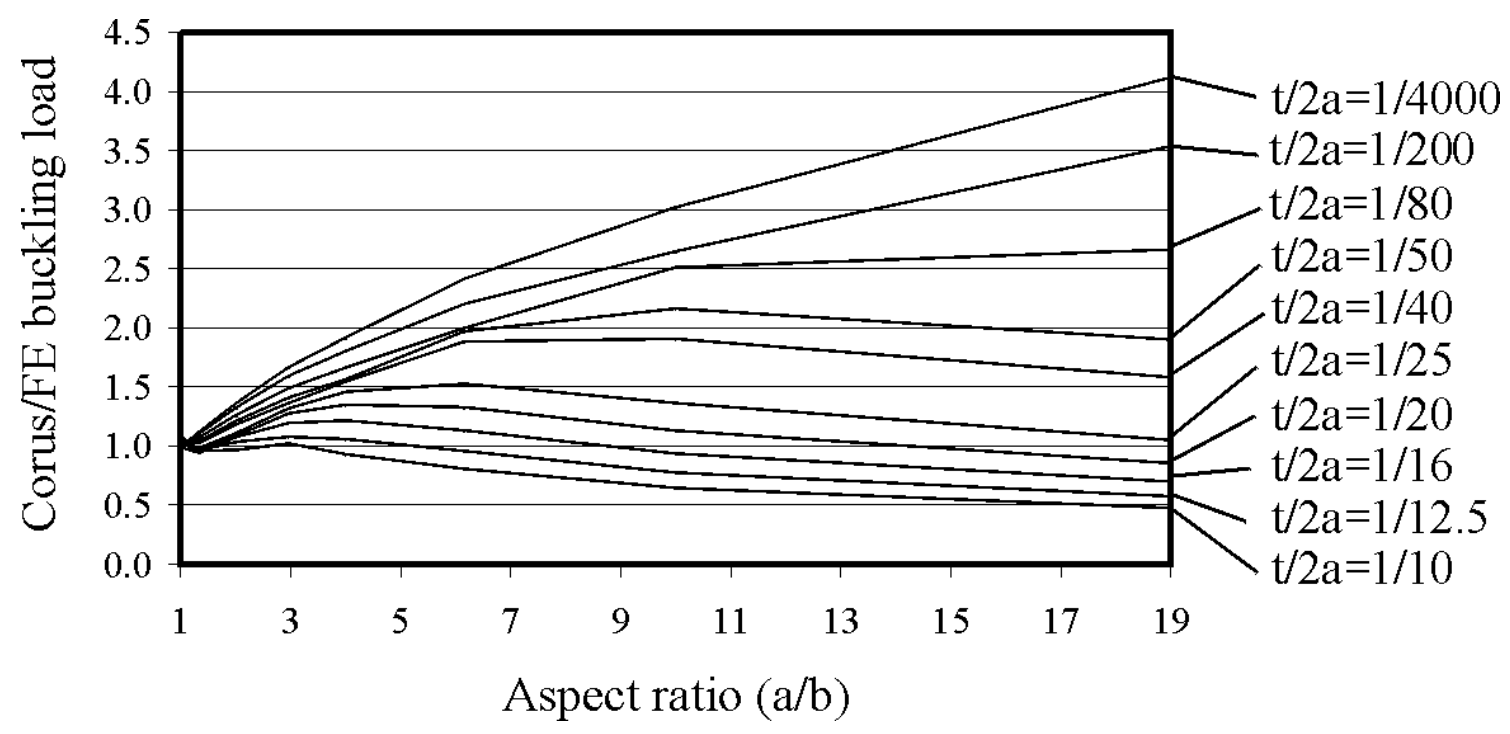

Fig. 7. Ratio between the elastic buckling load obtained with Corus assumption and that obtained by FE versus the aspect ratio of the EHS 
Cite this paper as: Ruiz-Teran AM, Gardner L, 2008, Elastic buckling of elliptical tubes, Thin-Walled Structures, Vol:46, ISSN:0263-8231, Pages:1304-1318 [DOI: 10.1016/j.tws.2008.01.036]

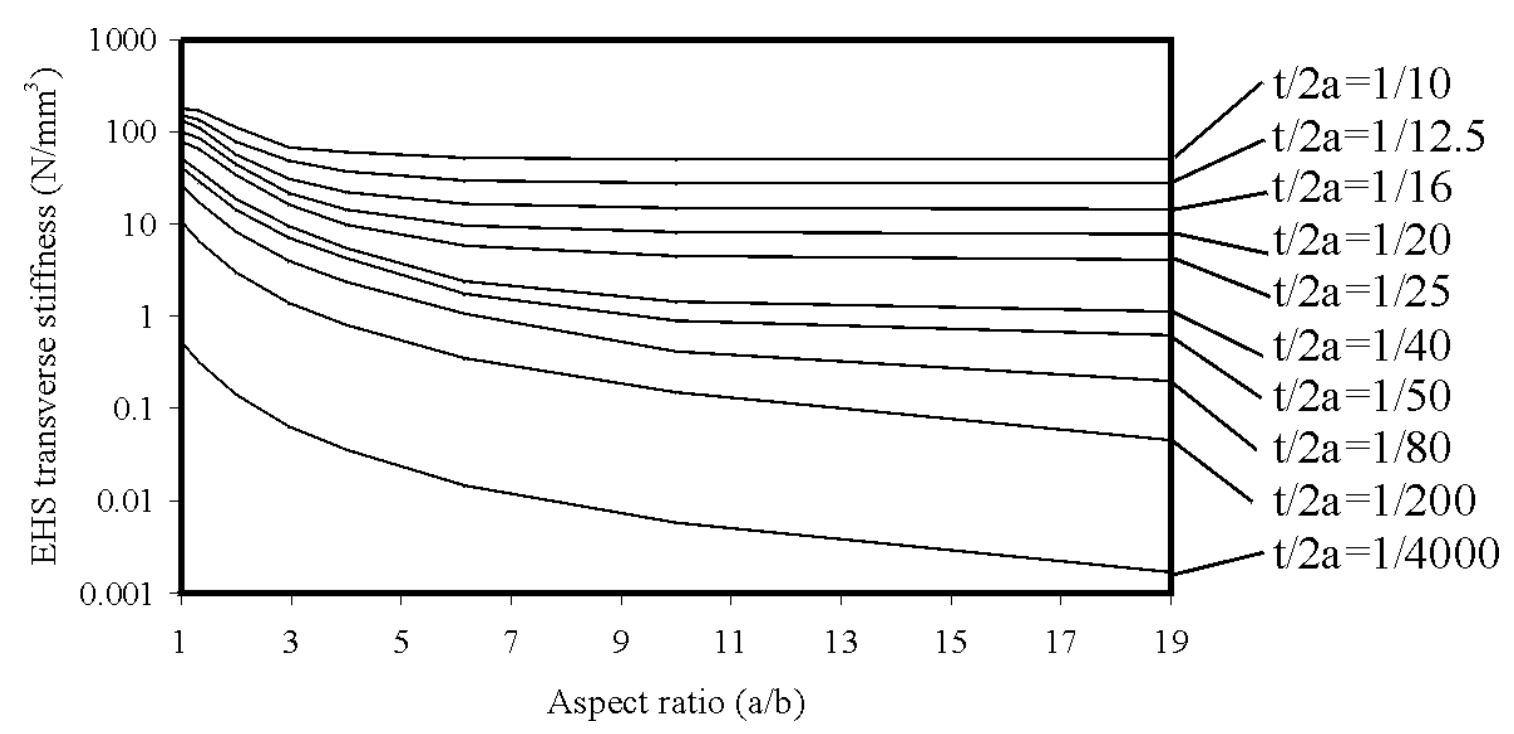

Fig. 8. Transverse stiffness of the EHS. 
Cite this paper as: Ruiz-Teran AM, Gardner L, 2008, Elastic buckling of elliptical tubes, Thin-Walled Structures, Vol:46, ISSN:0263-8231, Pages:1304-1318 [DOI: 10.1016/j.tws.2008.01.036]

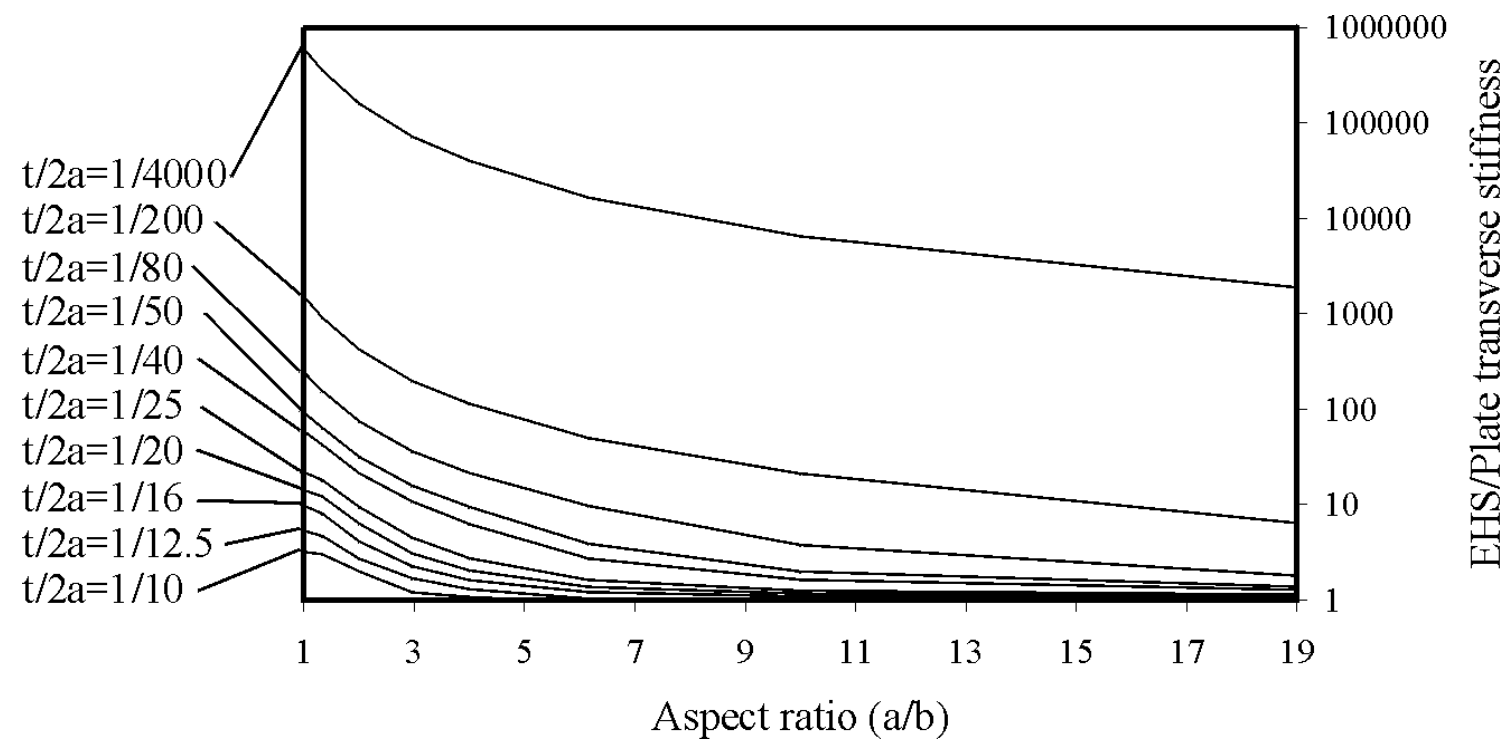

Fig. 9. Ratio between the EHS and plate transverse stiffness 
Cite this paper as: Ruiz-Teran AM, Gardner L, 2008, Elastic buckling of elliptical tubes, Thin-Walled Structures, Vol:46, ISSN:0263-8231, Pages:1304-1318 [DOI: 10.1016/j.tws.2008.01.036]

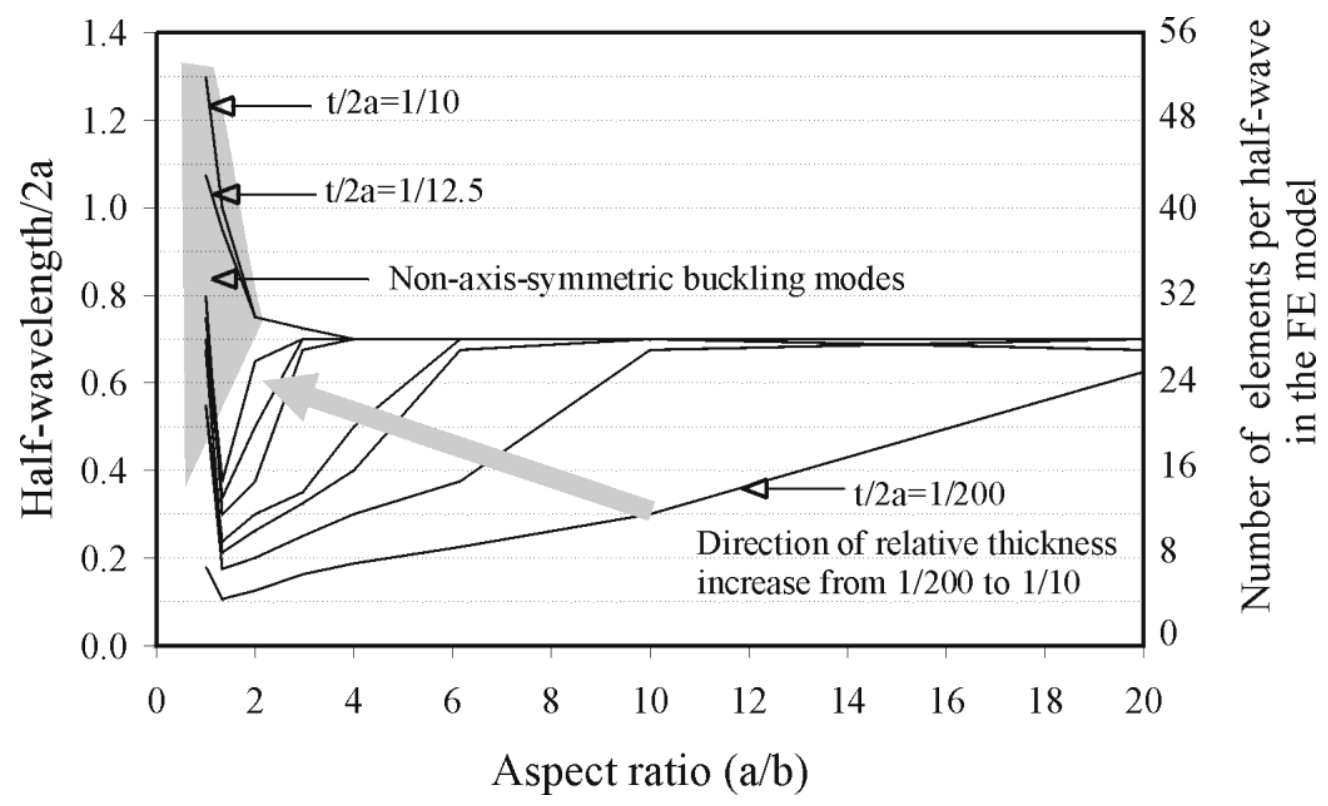

Fig. 10. Lengths of the longitudinal half-waves of EHS. 
Cite this paper as: Ruiz-Teran AM, Gardner L, 2008, Elastic buckling of elliptical tubes, Thin-Walled Structures, Vol:46, ISSN:0263-8231, Pages:1304-1318 [DOI: 10.1016/j.tws.2008.01.036]

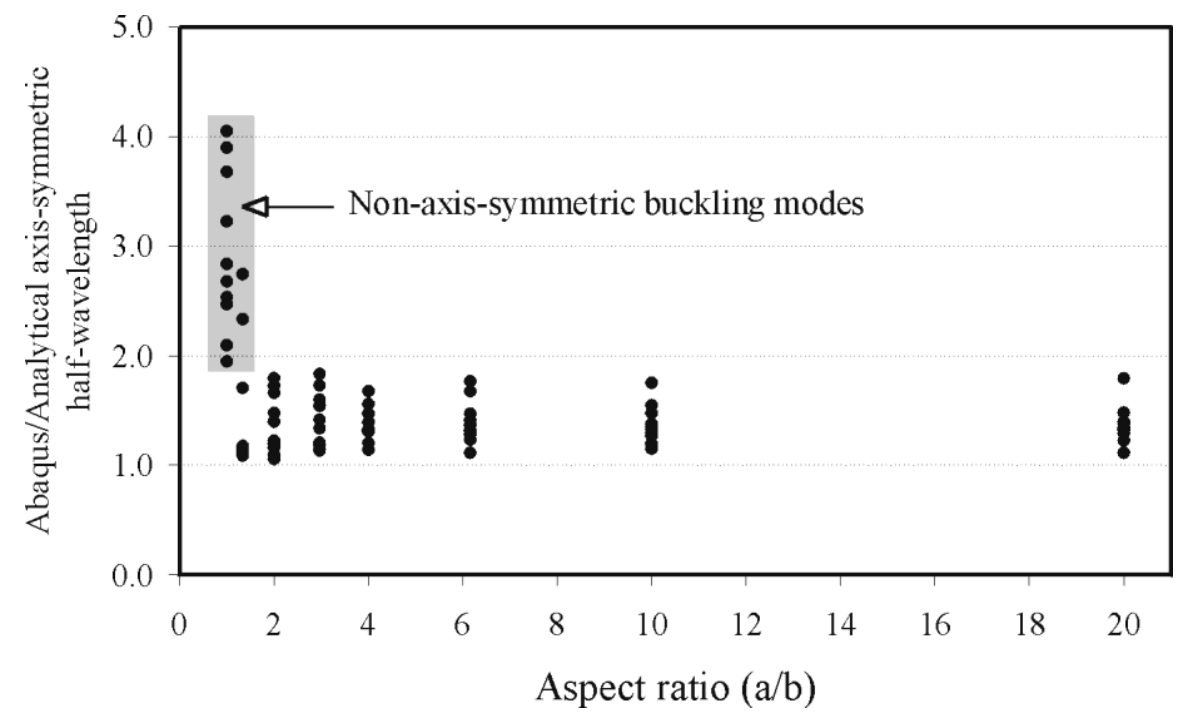

Fig. 11. Ratio between the numerical and the analytical longitudinal half-wavelength of EHS 
Cite this paper as: Ruiz-Teran AM, Gardner L, 2008, Elastic buckling of elliptical tubes, Thin-Walled Structures, Vol:46, ISSN:0263-8231, Pages:1304-1318 [DOI: 10.1016/j.tws.2008.01.036]

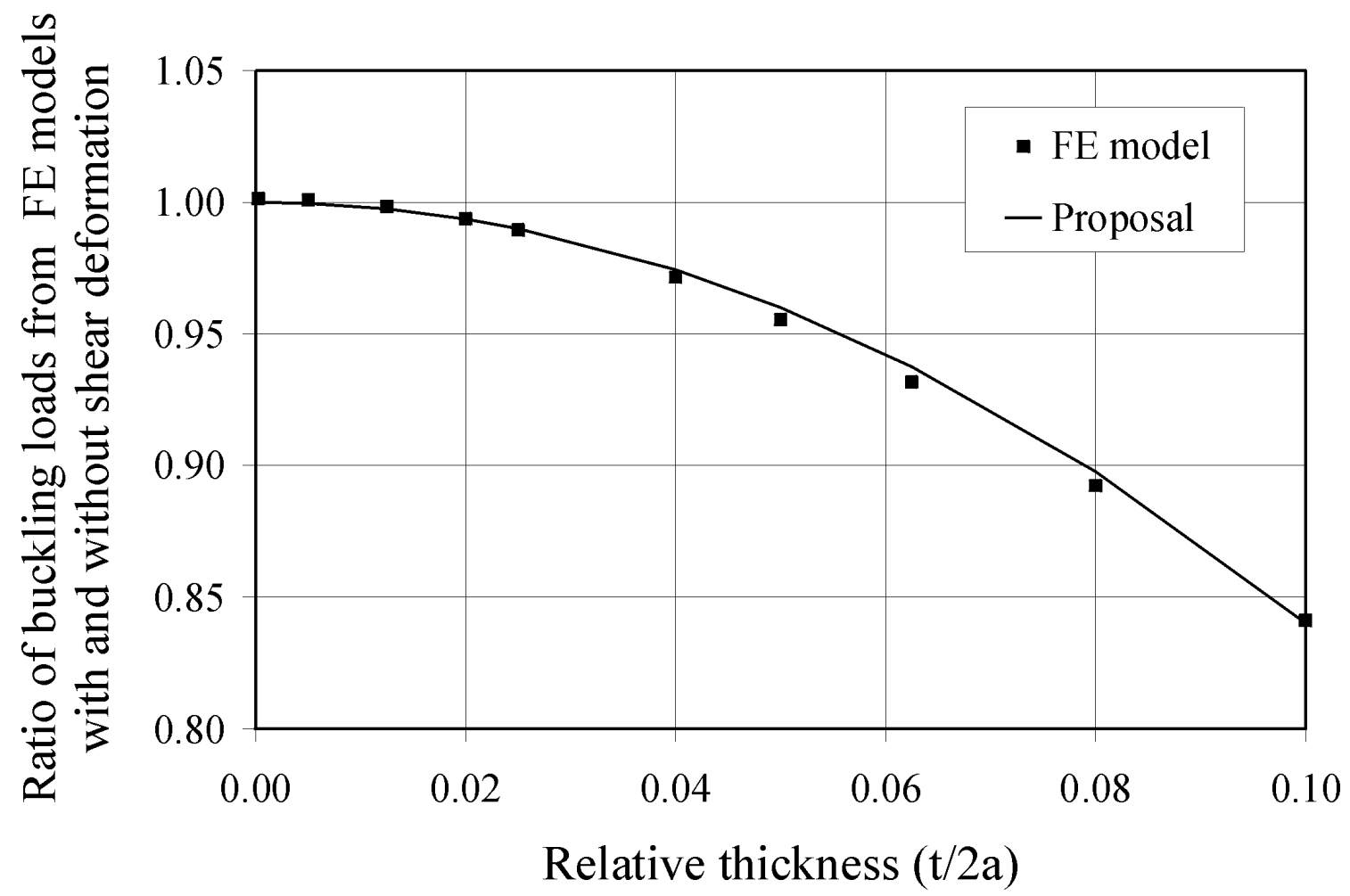

Fig. 12. Effect of the shear deformation on the elastic buckling stress of plates $(L / w \geq 2)$ 
a) 19th mode: CHS-like buckling mode
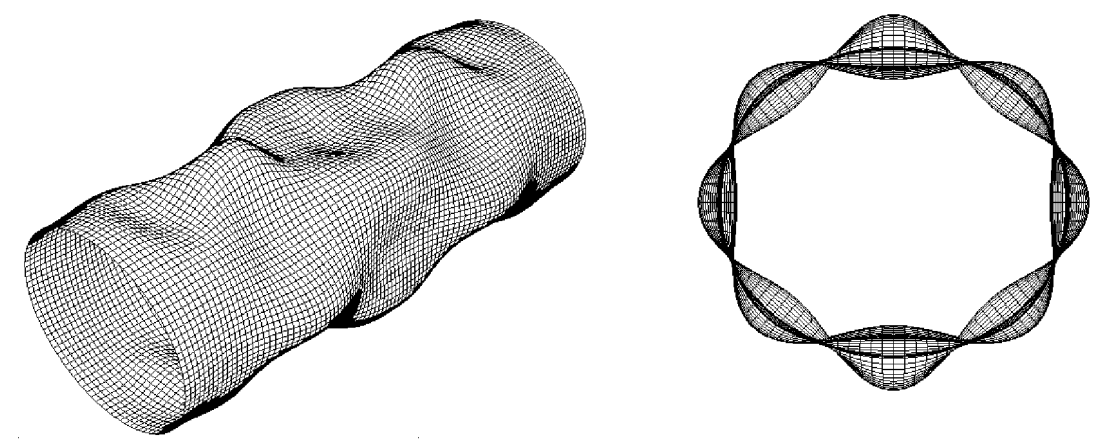

b) 1st mode: plate-like buckling mode
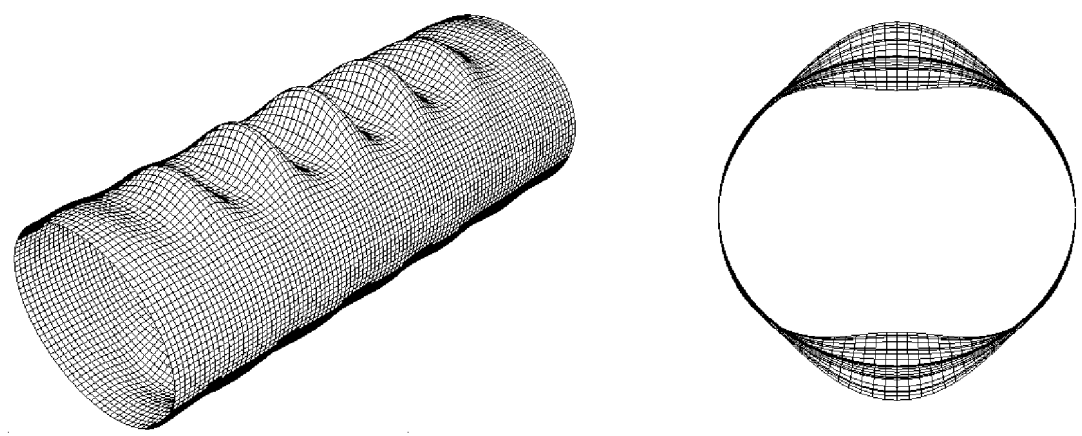

Fig. 13. Types of buckling modes for EHS $400 \times 350 \times 8$. a) CHS-like b) Plate-like. 
Cite this paper as: Ruiz-Teran AM, Gardner L, 2008, Elastic buckling of elliptical tubes, Thin-Walled Structures, Vol:46, ISSN:0263-8231, Pages:1304-1318 [DOI: 10.1016/j.tws.2008.01.036]

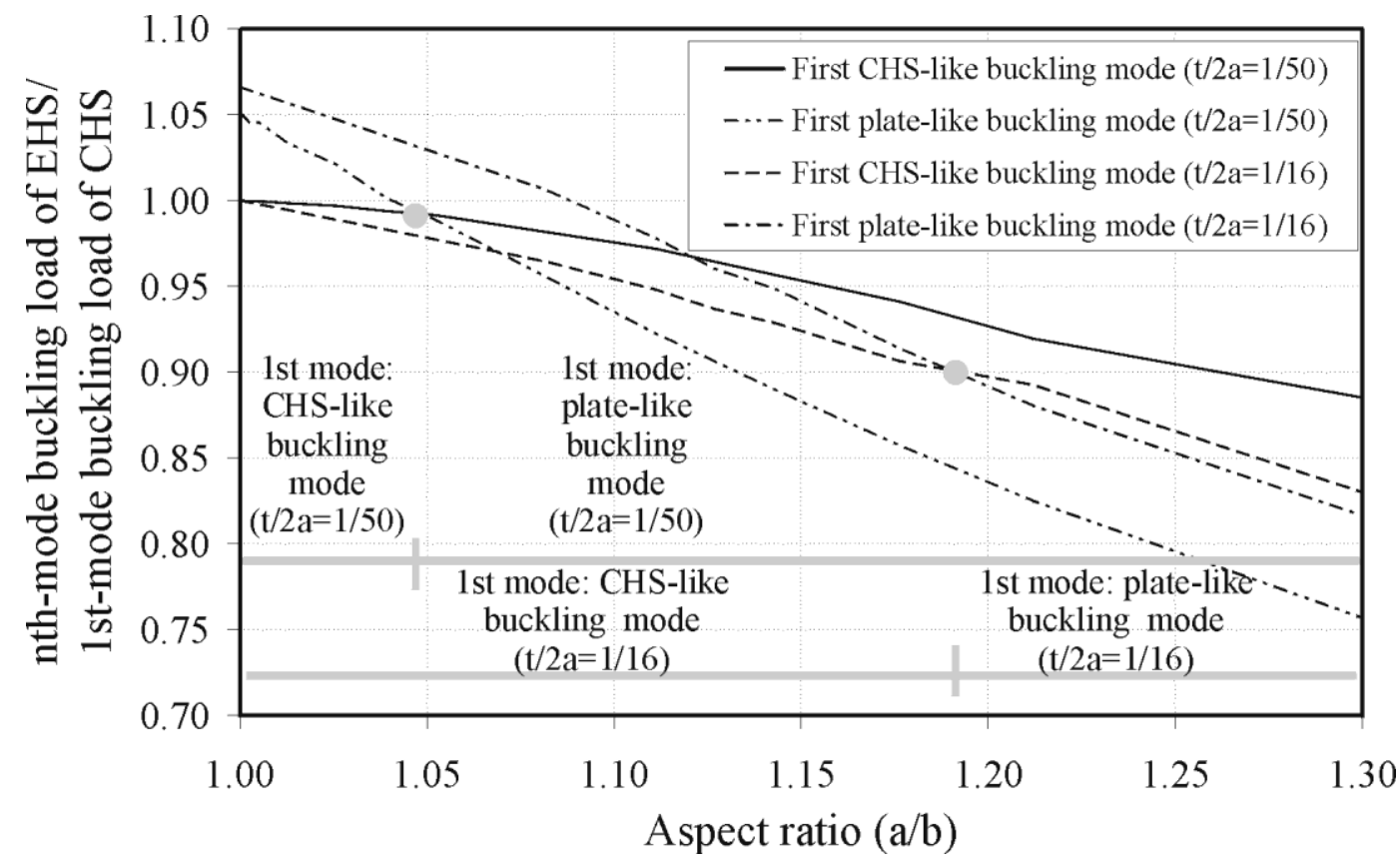

Fig. 14. Transition between CHS-like and plate-like buckling modes. 
Cite this paper as: Ruiz-Teran AM, Gardner L, 2008, Elastic buckling of elliptical tubes, Thin-Walled Structures, Vol:46, ISSN:0263-8231, Pages:1304-1318 [DOI: 10.1016/j.tws.2008.01.036]

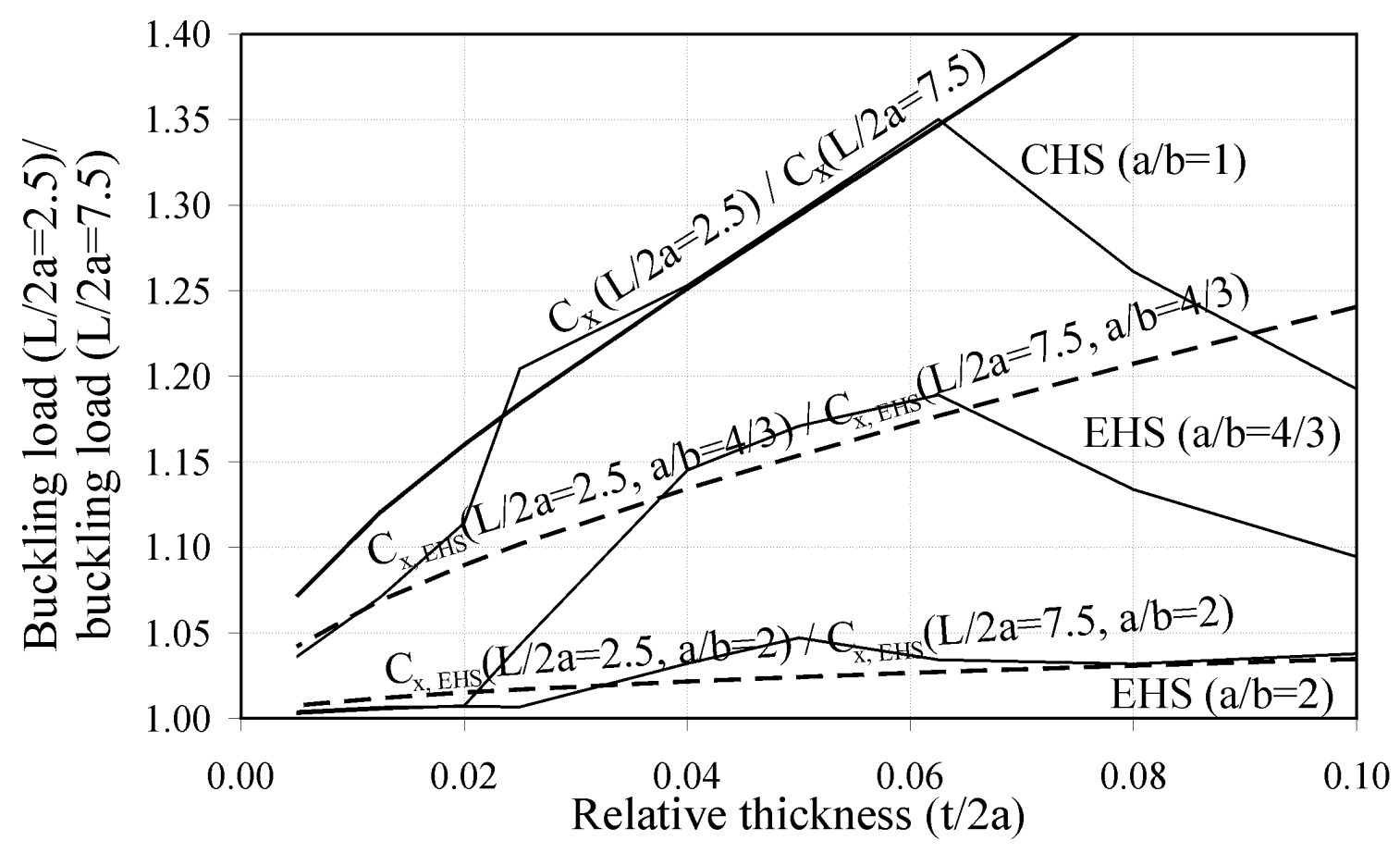

Fig. 15. Influence of length on elastic buckling load of EHS 
Cite this paper as: Ruiz-Teran AM, Gardner L, 2008, Elastic buckling of elliptical tubes, Thin-Walled Structures, Vol:46, ISSN:0263-8231, Pages:1304-1318 [DOI: 10.1016/j.tws.2008.01.036]

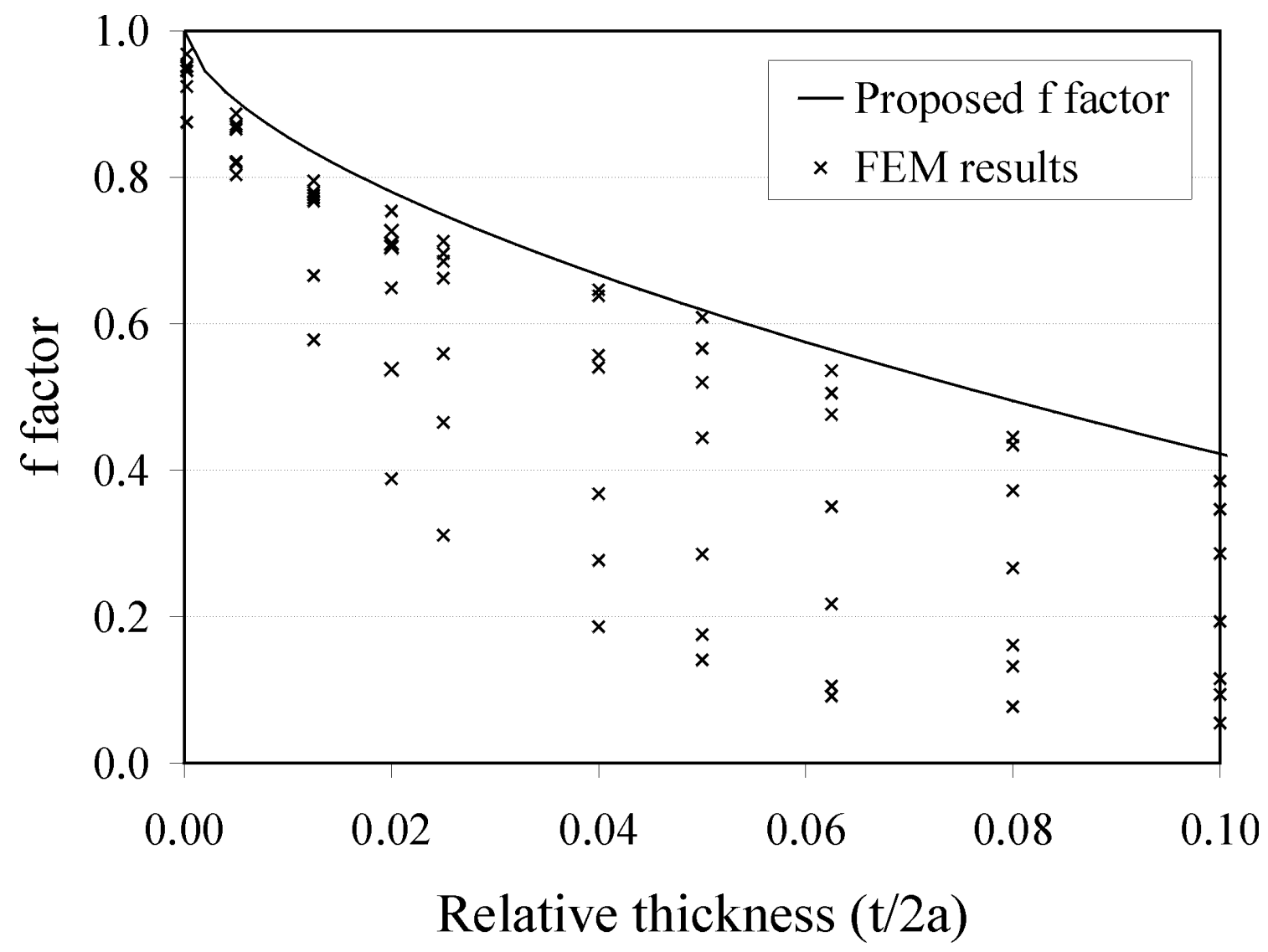

Fig. 16. $f$ factor for simple formula for determining the relative equivalent diameter of EHS. 
Cite this paper as: Ruiz-Teran AM, Gardner L, 2008, Elastic buckling of elliptical tubes, Thin-Walled Structures, Vol:46, ISSN:0263-8231, Pages:1304-1318 [DOI: 10.1016/j.tws.2008.01.036]

a)

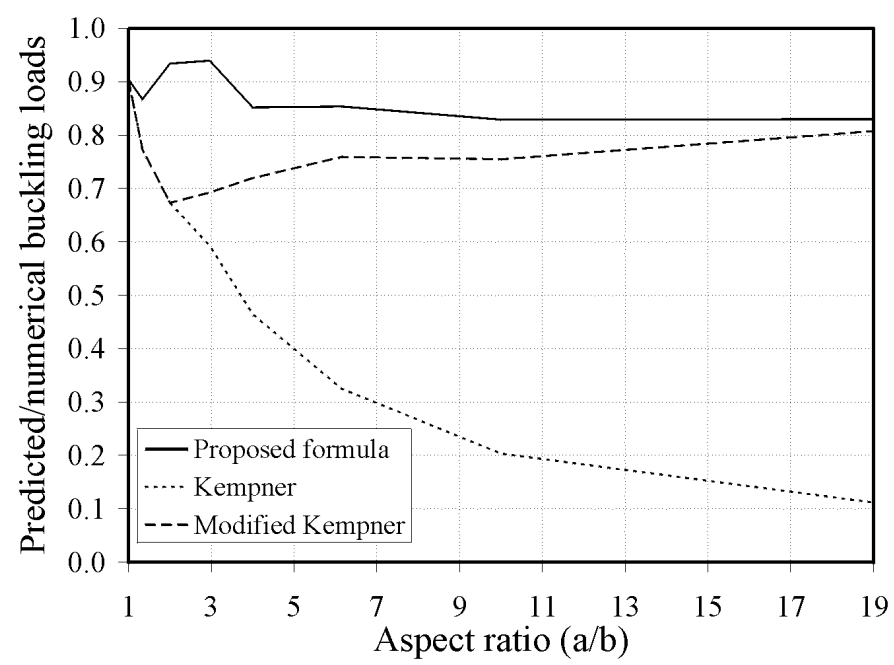

b)

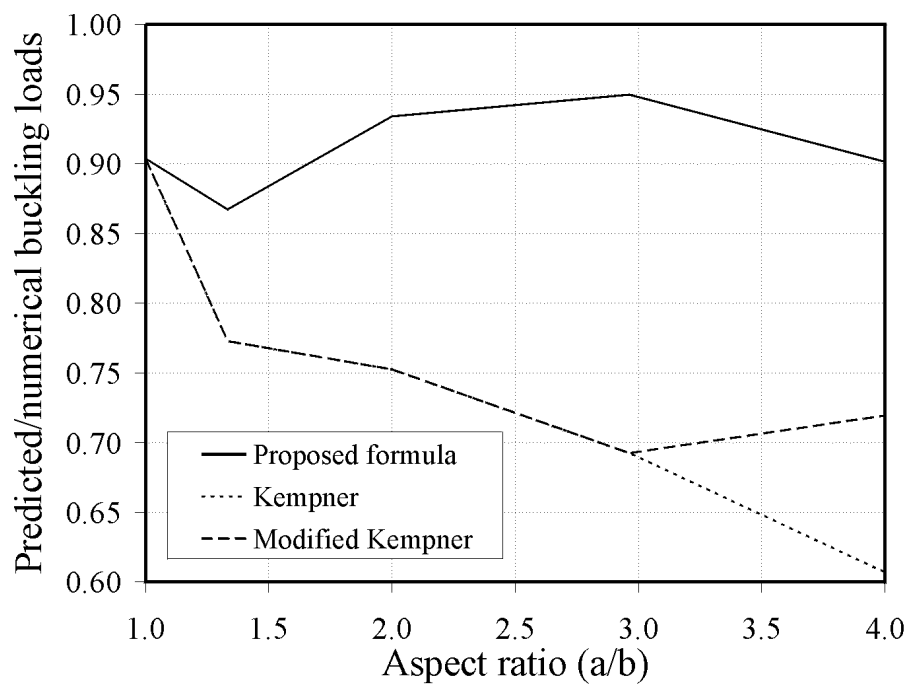

c)

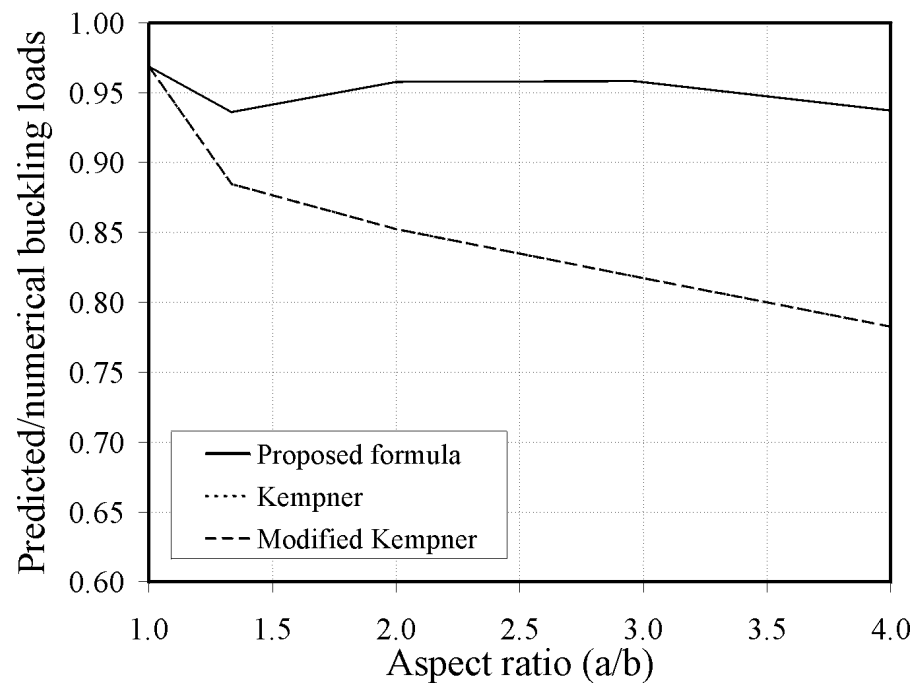

Fig. 17. Accuracy of the proposal for estimating the elastic buckling stress of EHS. a)

For the full range of the study $(t / 2 a \leq 1 / 10)$. $b)$ For a practical range $(a / b \leq 4$ and $t / 2 a \leq$ 1/16). c) For slender sections $(a / b \leq 4$ and $t / 2 a \leq 1 / 50)$ 
Cite this paper as: Ruiz-Teran AM, Gardner L, 2008, Elastic buckling of elliptical tubes, Thin-Walled Structures, Vol:46, ISSN:0263-8231, Pages:1304-1318 [DOI: 10.1016/j.tws.2008.01.036]

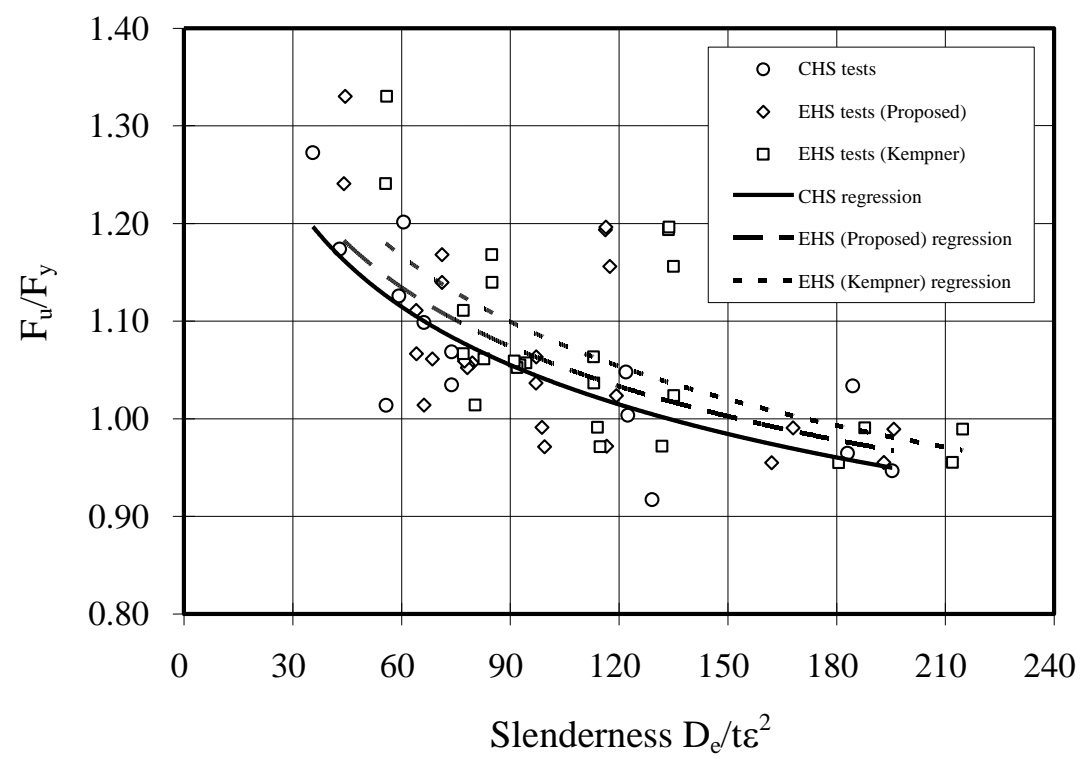

Fig. 18. Comparison of proposed and Kempner equivalent diameters employed in EHS slenderness parameters 